\title{
School as a workplace in Kenya: Evaluation of the Teachers Matter HIV/AIDS project
}

\author{
Karusa Kiragu \\ Caroline Mackenzie \\ Population Council \\ Jennifer Weiss \\ Murungaru Kimani \\ Debbie Gachuhi
}

Follow this and additional works at: https://knowledgecommons.popcouncil.org/departments_sbsr-hiv

Part of the Demography, Population, and Ecology Commons, Education Policy Commons, Health Policy Commons, Immune System Diseases Commons, International Public Health Commons, Medicine and Health Commons, Public Health Education and Promotion Commons, and the Virus Diseases Commons How does access to this work benefit you? Let us know!

\section{Recommended Citation}

Kiragu, Karusa, Caroline Mackenzie, Jennifer Weiss, Murungaru Kimani, and Debbie Gachuhi. 2008. "School as a workplace in Kenya: Evaluation of the Teachers Matter HIV/AIDS project," Horizons Final Report. Washington, DC: Population Council. 
School as a Workplace in Kenya:

Evaluation of the Teachers

Matter HIV/AIDS Project
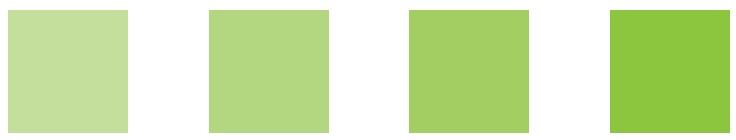

Horizons Program

PATH

Tulane University

University of Nairobi 


\title{
School as a Workplace in Kenya: Evaluation of the Teachers Matter HIV Intervention
}

\author{
Karusa Kiragu, Horizons/PATH \\ Caroline Mackenzie, Horizons/Population Council \\ Jennifer Weiss, Tulane University \\ Murungaru Kimani, University of Nairobi \\ Debbie Gachuhi, Independent Consultant
}

\section{Hgrizons}

USAID

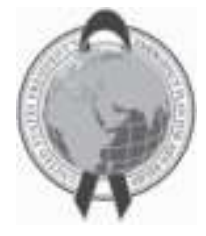

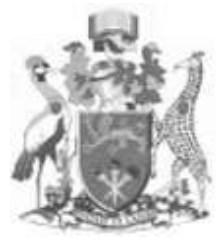




\section{Acknowledgments}

The authors would like to thank the following individuals and institutions for their invaluable contribution to the study: Isaac Thuita and Salome Maina of the Ministry of Education's AIDS Control Unit; Sarah Irungu and Oliver Munguti of the Teachers Service Commission's AIDS Control Unit; the District Education Offices of Thika, Kiambu, Kwale, and Kilifi; the District Staffing Office at Kwale and Kilifi; and the Kenya Institute of Education's AIDS Control Unit. We are also grateful for support from UNICEF, including Changu Mannathoko (formerly of UNICEF ESARO), as well as Roselyn Mutemi and Elias Noor (UNICEF-Kenya). We also thank the Project Advisory Committee members and especially the Kenya National Union of Teachers (KNUT), and the Center for British Teachers (CfBT) for their contributions in the early stages of the project. We make special mention of the Kenya Network of Positive Teachers (KENEPOTE), for their commitment to fellow teachers. We also recognize the Kenya AIDS and Drugs Alliance (KADA), for their work on the wellbeing of people living with HIV. We are grateful to Cornelius Mutangili for providing support supervision to the study, and George Odingo for data management. Gratitude is extended to Ellen Weiss and Scott Kellerman for their useful comments during the preparation of this manuscript. We would also like to thank Sherry Hutchinson for the layout.

We convey heartfelt thanks to all the interviewers, peer educators, and school managers for the crucial role they played in making this study a success. We appreciate the support of the head teachers in the participating schools. Special thanks go to the individual teachers who completed the questionnaires and agreed to answer sensitive questions about their lives.

Finally, the authors are grateful to UNICEF for funding the baseline study, and to USAID/PEPFAR for funding the intervention and follow-up phases of the study.

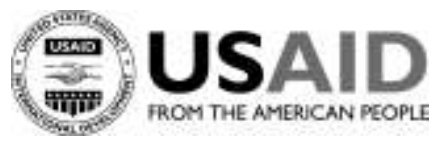
necessarily reflect the views of USAID or the United States Government.
This study and final report were made possible by the President's Emergency Plan for AIDS Relief and the generous support of the American people through the United States Agency for International Development (USAID) under the terms of Cooperative Agreement No. HRN-A00-97-00012-00. The contents are the responsibility of the Horizons Program and do not

Published in February 2008.

\section{(2) Population Council}

The Population Council is an international, non-profit, nongovernmental institution that seeks to improve the well-being and reproductive health of current and future generations around the world and to help achieve a humane, equitable, and sustainable balance between people and resources. The Council conducts biomedical, social science, and public health research and helps build research capacities in developing countries. Established in 1952, the Council is governed by an international board of trustees. Its New York headquarters supports a global network of regional and country offices.

Copyright @ 2008. The Population Council Inc.

Suggested citation: Kiragu, Karusa, Caroline Mackenzie, Jennifer Weiss, Murungaru Kimani, and Debbie Gachuhi. 2008. "School as a workplace in Kenya: Evaluation of the Teachers Matter HIV/AIDS project," Horizons Final Report. Washington, DC: Population Council.

This document may be reproduced in whole or in part without permission of the Population Council provided full source citation is given and the reproduction is not for commercial purposes. 


\section{Table of Contents}

\section{Abbreviations}

Executive Summary $\quad 1$

$\begin{array}{ll}\text { Background } & 7\end{array}$

$\begin{array}{ll}\text { Workplace programs for teachers } & 7\end{array}$

Education sector policies on HIV

Methods and Study Sample $\quad 10$

$\begin{array}{lr}\text { Research questions } & 10\end{array}$

$\begin{array}{ll}\text { Study methods } & 10\end{array}$

Study sample $\quad 11$

Description of the Intervention 13

$\begin{array}{ll}\text { Theoretical framework } & 13\end{array}$

$\begin{array}{lr}\text { Program implementation } & 13\end{array}$

$\begin{array}{ll}\text { Results } & 20\end{array}$

Exposure to Teachers Matter 20

Effects of Teachers Matter intervention on selected outcome measures 23

Discussion and Recommendations $\quad 38$

Successes $\quad 38$

$\begin{array}{ll}\text { Challenges } & 39\end{array}$

Lessons learned $\quad 40$

$\begin{array}{ll}\text { Appendices } & 43\end{array}$

$\begin{array}{ll}\text { References } & 45\end{array}$ 


\section{Abbreviations}

$\begin{array}{ll}\text { AFT } & \text { American Federation of Teachers } \\ \text { AIDS } & \text { Acquired Immune Deficiency Syndrome } \\ \text { ART } & \text { Antiretroviral therapy } \\ \text { ARV } & \text { Antiretroviral } \\ \text { BCC } & \text { Behavior change communication } \\ \text { CI } & \text { Confidence interval } \\ \text { FGD } & \text { Focus group discussion } \\ \text { HIV } & \text { Human Immunodeficiency Virus } \\ \text { KADA } & \text { Kenya AIDS and Drugs Alliance } \\ \text { KNUT } & \text { Kenya National Union of Teachers } \\ \text { MOE } & \text { Ministry of Education } \\ \text { KIE } & \text { Kenya Institute of Education } \\ \text { KENEPOTE } & \text { Kenya Network of Positive Teachers } \\ \text { NUD*IST } & \text { Non-Numeric Unstructured Data * Indexing, Searching and Theorizing } \\ \text { NS } & \text { Not significant } \\ \text { OR } & \text { Odds ratio } \\ \text { PEP } & \text { Post-exposure prophylaxis } \\ \text { STI } & \text { Sexually transmitted infection } \\ \text { TSC } & \text { Teacher Service Commission } \\ \text { VCT } & \text { Voluntary testing and counseling }\end{array}$




\section{Executive Summary}

Countless HIV interventions rely on teachers to deliver vital prevention messages to their students but do not target the teachers as direct beneficiaries, even though the teachers themselves are at risk of HIV infection. In 2004, the Horizons Program of Population Council embarked on an operations research initiative to test the feasibility of implementing a teacher-centered workplace program based in schools. The study was conducted in partnership with the Ministry of Education (MOE), the Kenya Institute of Education (KIE), the Teachers Service Commission (TSC), and UNICEF. Called "Teachers Matter," the project's main audience was primary and secondary school teachers. The purpose of the research was to assess whether such a program would improve teachers' HIV-related knowledge, attitudes, and behaviors; increase the proportion of teachers seeking voluntary testing and counseling (VCT); and enhance their ability to cope with HIV-related issues in the workplace.

\section{Methods}

A quasi-experimental design was employed to assess the impact of Teachers Matter. Quantitative data were collected from 120 schools in two intervention sites (60 schools) and two comparison sites (60 schools) in Central and Coast provinces. The baseline survey was conducted in October 2004 and the follow up in March 2007. Data were gathered using an anonymous, pre-tested, self-administered questionnaire. The sample comprised 1,237 teachers at baseline and 1,307 teachers at follow up. Qualitative data were also collected through a total of 16 focus group discussions with teachers and peer educators.

\section{Description of the Intervention}

Teachers Matter is a peer-led education program, guided by a 10 -unit manual ${ }^{1}$. The manual drew on two theories of behavior change: The Transtheoretical Model (TM) (Peterson and DiClemente 2000), and the Theory of Gender and Power (Connell 1987). Before the intervention, head teachers from each participating school were given a sensitization training to seek their input and support for the program. Subsequently, each school selected a teacher to be a peer educator; these peer educators received a oneweek training on how to use the manual. Throughout the 12-month intervention, peer educators were supported by quarterly visits from the Teachers Matter study monitor, and received a refresher course midway through the training.

The manual had 30 units that were to be covered throughout the academic year (about 36 weeks). Peer educators were given freedom to schedule intervention activities based on the needs of their respective schools. Most meetings with teachers were held once a week and lasted from 30 to 90 minutes. Peer educators were supplied with educational brochures, samples of condoms, and samples of antiretrovirals (ARVs) to show to teachers; specially-made calendars featuring teachers; and other educational materials. Teachers were also given copies of the Education Sector Policy on HIV and AIDS booklet that had been launched in 2004. In addition to regular meetings, teachers also participated in community activities to increase AIDS awareness such as football tournaments and World AIDS Day events. The project sought

\footnotetext{
${ }^{1}$ The manual was adapted from the Life Skills Manual for Guide Leaders developed by the Kenya Girl Guides Association.
} 


\section{Hgrizons}

opportunities to involve organizations for people living with HIV, and commissioned such a group to produce peer education bags and penis models.

During peer educator training, a mobile VCT team provided services for free to the teachers. Of the 120 teachers attending the training, 40 (33 percent) got tested for HIV for the first time.

Once the follow-up evaluation was conducted, Teachers Matter behavior change communication (BCC) materials were also provided to the 60 comparison schools. Collectively, the project reached over 2,700 teachers in both intervention and comparison schools. The intervention cost approximately $\$ 42,500$ which covered preparation, printing and distribution of $\mathrm{BCC}$ materials, training of the peer educators (including materials, transport and accommodation), sensitization of headteachers, and offering mobile VCT services. This translates into roughly $\$ 16$ per teacher reached.

Challenges encountered included an abrupt change in the funding environment, leading to sharp financial cutbacks for operations research. This led to a17-month lag between the baseline survey and the commencement of Teachers Matter.

\section{Data Analysis}

Both baseline and follow-up data were double-entered using EPIDATA. Data were analyzed with STATA v9, and SPSS v15 using univariate, bivariate, and multivariate methods. For bivariate analysis, the measure of association was the chi-square and its p-value. For multivariate analysis, the statistical technique was logistic regression, and the measure of association was the odds ratio. Exposure to the intervention was classified into three groups: unexposed (teachers in the intervention schools who did not attend any meetings, and all those in the comparison schools), moderately exposed (intervention school teachers who attended some of the meetings) and highly exposed (teachers in the intervention schools who attended all meetings $)^{2}$. This allowed a dose-response analysis of the associations. Qualitative data were analyzed with NUD*IST.

\section{Key Findings}

\section{Teachers were greatly interested in the intervention and found it beneficial.}

Almost all (92 percent) of the respondents in the intervention schools had heard of Teachers Matter at follow up, and 80 percent had participated in it. Thus the intervention was able to reach four out of five teachers it targeted. Participating teachers listed several kinds of information they obtained from the project, including basic information about HIV, where to get tested for HIV, male and female condoms, and how to live positively with HIV. Seventy-one percent of the target population said they took further action related to HIV as a result of the project, such as remaining monogamous, talking with family members or friends about HIV, getting tested for HIV, abstaining, or using condoms. Nearly 75 percent of the teachers recommended that the program continue.

\footnotetext{
2 Attendance was measured by the answer to the following question: "How often did you attend Teachers Matter since it started?" Answers were $1=$ Every meeting; 2 = Most meetings; 3 = About half the meetings; $4=$ Rarely/never. Those attending most or some meetings were combined to form the "some" group.
} 


\section{The intervention was well implemented and provided useful lessons for the future.}

In general, teachers were receptive to Teachers Matter and keen to discuss how HIV was affecting their lives. Most attended enthusiastically and found the interactive nature of the sessions enjoyable and educational. Peer educators demonstrated innovation and resourcefulness in their ability to reach their fellow teachers. However, there were a few challenges at the beginning: a few teachers were skeptical that they would learn anything new, but this number gradually declined. Some teachers expected financial compensation for attending the meetings, but this tapered off once it was clarified that no such incentives were available. Finding time in a busy school schedule was challenging. In addition, many teachers were still uncomfortable discussing sexual matters, especially topics like condoms. Also, due to the heterogeneity of the teaching staff, it was sometimes difficult for a peer educator to relate to all the teachers, and this made discussions of some sensitive topics awkward. In some cases, teachers, and even peer educators, were reluctant to participate actively, lest they draw undue attention to themselves and raise questions about their own HIV status. Supportive monitoring and support from head teachers often addressed these issues successfully. Endorsement from the district education offices greatly facilitated acceptance of the project. The mid-term peer educator training was a valued opportunity to share these experiences and find appropriate solutions.

\section{Awareness of the Education Sector Policy on HIV and AIDS increased among participating teachers.}

Teachers Matter was effective in enhancing familiarity with the Education Sector Policy on HIV and AIDS. During the baseline survey, about 42 percent of teachers in the intervention sites had heard of the policy, and this had risen to 62 percent at follow up. However, in the comparison sites, 40 percent had heard of the policy at the baseline, but the percent remained unchanged (39 percent) during follow up. The results were especially significant when examining readership of the booklet: teachers who attended some of the Teachers Matter meetings were 2.0 times more likely to have read the policy compared to those who did not attend (CI 1.0 - 3.9), while those who attended all the meetings were 5.7 times more likely (CI: $2.8-11.2)$. Thus exposure to the intervention was associated with a greater utilization of the policy booklet.

\section{Participants perceived improvement in their schools' and fellow teachers' abilities to cope with HIV issues.}

Respondents in schools where Teachers Matter was implemented reported significantly greater progress in how adept the teachers, and the school's management, had become at coping with HIV issues compared to a year earlier. About 35 percent of teachers in the intervention schools reported "great improvement" in their being able to cope with HIV in the school setting, compared to 26 percent of their counterparts in the comparison sites. Regression analysis showed that compared to those who were not exposed to Teachers Matter, respondents who attended all the meetings were 3.6 times more likely to report "great improvement" in teachers' HIV coping abilities (CI: 1.9-6.7).

Similar results were also obtained regarding management's coping efficacy: 28 percent of teachers in intervention schools reported "great improvement" in management's ability to cope with HIV compared to a year ago, while 19 percent of those in comparison schools reported so. Regression analysis showed 


\section{Hgrizons}

that compared to those who were not exposed to Teachers Matter, respondents who attended all the meetings were 1.7 times more likely to report "great improvement" (CI: 0.9-3.2).

\section{There was a decline in perceived risk of HIV.}

Baseline data showed that teachers feared being infected at work, such as being exposed to HIV when dealing with school-related injuries during sports, or simply while separating scuffling classmates. In addition, the fact that primary school education is now free in Kenya means that many children whose parents could not afford school earlier, including some HIV-infected children, have now enrolled. In response, Teachers Matter educated teachers on HIV transmission, in an effort to allay their fears. After the project, the percent of teachers who were "very concerned" about becoming infected with HIV while at work declined from 65 percent to 57 percent in the intervention schools $(\mathrm{p}<.017)$, but there was no change in the comparison schools (61 percent both rounds, $\mathrm{p}=0.726)$. However, it is worth noting that even after the intervention, 57 percent of teachers still consider their HIV risk at work high. One possible reason could be because less than 10 percent reported functional and fully-stocked first aid kits, as recommended by the Education Sector Policy on HIV and AIDS.

\section{There was an improvement in the awareness of post-exposure prophylaxis.}

Because post-exposure prophylaxis (PEP) is now available in Kenya, Teachers Matter provided an opportunity to explain the purpose of this medication and procedures for accessing it. Results show that after the intervention, many teachers became better informed about PEP. At baseline, only 4 percent of teachers in the intervention group said they knew what PEP was; of those, 24 percent correctly explained what it was. At follow up, 25 percent of the same group reported knowing what it was and 50 percent of them were correct $(\mathrm{p}<.0001)$. There were no significant gains made in knowledge of PEP in the comparison group ( 2 percent aware of it at baseline vs. 3 percent at follow up). Multivariate analysis showed that teachers who attended some of the meetings were 2.6 times more likely to know what PEP was (CI: 1.2-5.9), while those who attended all the meetings were 6.7 times more likely to know, compared to their counterparts who did not attend any meetings (CI: 3.0-15.2).

\section{There were improvements in awareness and attitudes toward male and female condoms.}

After participating in the intervention, teachers demonstrated a statistically significant increase in positive attitudes toward male condoms from 49 to 64 percent ( $\mathrm{p}<.0001$ ), compared to no significant change in the comparison group (52 to 58 percent, $\mathrm{p}=0.071$ ). Teachers Matter also effectively conveyed information about female condoms, as there was a significant increase in those who had seen a female condom, from 42 to 77 percent in the intervention group ( $<<.0001)$, compared to a smaller increase in the comparison group, from 47 to 55 percent $(\mathrm{p}<.01)$.

Multivariate analysis showed that teachers who attended all the Teachers Matter meetings were 1.7 times more likely to have favorable attitudes toward male condoms (CI: 0.9-3.1) In addition, those who attended all meetings were 5.3 times more likely to have seen a female condom (CI: 2.5-11.0). 


\section{There was an increase in HIV testing, but the majority of teachers still did not know their HIV status or that of their partners.}

There was an increase in HIV testing, but the increment occurred in both intervention and comparison sites ( 24 percent to 39 percent in the intervention sites versus 25 percent to 41 percent in the comparison sites). Multivariate analysis was not able to document a correlation between exposure to the intervention and HIV testing, suggesting that factors outside the intervention may have been more influential. The data show also that many teachers still feared being tested and that, although gains were made, only 43 percent of untested teachers in both the intervention and comparison groups wanted to be tested. The program did not impact on the likelihood of partners getting tested, suggesting that activities more specifically directed at partners and couples would be needed for this change to occur.

\section{Most teachers with multiple partners were not protecting themselves from HIV.}

Although questions about detailed sexual risk-taking among the study participants elicited a non-response rate of about 15 percent, available data showed that at follow up, 14 percent of respondents in the intervention schools had multiple partners in the 12 months preceding the research. In the comparison schools, about 17 percent did as well. However, 90 percent of such teachers in the intervention schools and 80 percent of their counterparts in the comparison schools said they did not use condoms "always" during these encounters. Because inconsistent condom use does not confer adequate protection from HIV, programs are needed to help these teachers protect themselves effectively if they choose to have multiple sex partners. Multivariate analysis showed that there was no association between having multiple partners and exposure to the intervention, suggesting that more concerted efforts would be needed for a behavioral effect to be achieved. Similarly, there was no association between the intervention and HIV testing among teachers with multiple partners, suggesting that further efforts are needed to persuade such individuals to get tested.

\section{Nearly 40 percent of teachers have experienced an AIDS-related death in their families.}

Teachers continue to be strongly affected by HIV in their personal lives, as many of their relatives have been either infected with HIV or have died of AIDS. Indeed nearly 40 percent of teachers in the intervention and comparison schools at follow up were aware of an "immediate family member" who had died of AIDS. There was an increase in the percentage of teachers reporting familial HIV in both intervention (30 percent to 41 percent) and comparison (35 percent to 39 percent) groups. The larger increment in the intervention site could be reflecting greater willingness to disclose this information. For example, Teachers Matter gave teachers information to help care for ailing relatives and many teachers may have become a magnet for providing care in the family. Teachers were also encouraged to be empathetic to people living with HIV, and this could also have led to more PLHIV seeking them out for assistance. In addition, teachers may have become more informed about HIV and better able to identify HIV as a cause of death of a family member that might not have previously disclosed their status. Whatever the explanation, it is clear that many teachers have been directly affected by HIV. 


\section{Hgrizons}

\section{The intervention was associated with improvements in HIV knowledge, but reduction of stigma occurred in both the intervention and comparison groups.}

Significant gains were made in general HIV knowledge, increasing in similar proportions in both intervention and comparison schools. However, regression analysis showed that those who attended all Teachers Matter sessions were 2.0 times more likely to have a high level of HIV knowledge, but those who only attended some sessions were no different than those who did not attend. There were also improvements in stigma, but this occurred in both the intervention and comparison groups. Regression analysis did not identify an association between stigma and the intervention.

\section{Concerns remained about HIV-related confidentiality at work.}

Analysis shows that much ambiguity remained regarding job security if HIV positive and recourse for breaches of confidentiality. At follow up, over half of the teachers in both intervention and comparison schools reported not knowing what recourse there was if there was a breach of confidentiality, in part because the present policy is largely unclear on this issue.

\section{Conclusions}

The impact of HIV on the education sector in Kenya has prompted key actors to explore appropriate responses. Already the Kenyan National Union of Teachers (KNUT) is implementing a peer education program in selected districts. Because many interventions may not have a strong evaluation component, this report may offer a glimpse of possible outcomes, based on similar peer education strategies.

The results suggest that a teacher-centered peer education program can be successful in increasing an overall level of openness and comfort surrounding HIV issues in the school setting, familiarizing the target population with previously unknown technologies such as PEP and female condoms, and improving the work environment so that teachers can better cope with HIV issues that may emerge. Teachers who participated fully in Teachers Matter had an advantage over their colleagues, and thus were more likely to have benefited from the intervention. Therefore programs seeking to implement a similar intervention may get the most mileage if they structure it in a manner to maximize teacher participation, for example by incorporating it into the school time table, or recognizing participation with certificates or other incentives. The support of the school management was a significant determinant in how well Teachers Matter was implemented. The support of the Ministry of Education at the national and district level greatly facilitated the implementation of the intervention. Because four out of ten teachers have personally experienced a death from HIV in their immediate families, activities to help teachers cope in their individual lives may be as important as activities to help them educate their students. 


\section{Background}

As the HIV epidemic continues to spread through sub-Saharan Africa, one of the most devastating features has been its effect on the labor force. Individuals between the ages of 15 and 49 years have the highest HIV infection rate and also make up the bulk of the workforce. AIDS strikes people in the prime of their lives and earning capacity, resulting in devastating effects at the individual and societal levels. On a macro level, AIDS takes its toll on all aspects of the workforce, resulting in greater difficulties delivering services and products, reduced profits, strains on human resource management, and weakened operations efficiency due to losses in employees from HIV-related illness and death (UNAIDS 2006).

The impact of HIV may be particularly pronounced in the education sector. Mortality due to AIDS among primary and secondary school teachers results in decreased staffing and reduced ability to deliver educational outputs. Although reliable data regarding AIDS-related deaths among teachers in Kenya is scarce, it is estimated that between 1995 and 1999, the number of teacher deaths tripled, with AIDS being the largest hypothesized contributor (Kelly 2000). A more recent analysis by the International Labor Organization (ILO) suggests that Kenya will be second only to South Africa in the sheer number of teachers dying from AIDS by 2010 (Cohen 2002). The Kenya data is consistent with high teacher mortality and morbidity recorded in other African countries. In Zambia, for example, one study estimates that 840 teachers died from AIDS in 1999, equivalent to 46 percent of all teachers trained that year (Grassly et al. 2003). In Botswana, 35-40 percent of teachers are thought to be infected with HIV (Clark 2001). In South Africa, the local teachers' union documents a 43 percent increase in teacher deaths between 2000 and 2001 (Mail and Guardian 2001), while in Malawi, reports say that 7,500 teachers die of AIDS annually (Comtex Newswire 2002). More positive news however is offered by Bennel (2006), who notes that even in high prevalence southern African countries, teacher mortality is falling or stabilizing in part due to behavior change and access to treatment.

Teacher morbidity takes a heavy toll on schools; prolonged teacher absenteeism due to AIDS-related illness leads to a loss of learning time among students and an overall decrease in the quality of teaching. Morbidity and mortality among teachers is especially harmful in rural areas, where schools may only employ one or two teachers. Another impact of HIV on the education sector is economic: analysts suggest that in Africa, each death due to AIDS is preceded by about 18 months of disability (Goliber 2000). Because it is unethical to dismiss sick teachers, such disability means that the education sector must support a large number of unproductive persons, resulting in severe economic loss.

HIV also contributes to a great deal of personal stress among teachers as their personal and professional lives are inevitably affected by the epidemic. Such stress in turn affects the quality of instruction in the classroom and may strain teacher-community relationships. The impact of HIV on teachers in Kenya is especially important to consider, as teachers represent Kenya's single largest workforce, comprising 240,000 professionals (Kimani et al. 2005).

\section{Workplace Programs for Teachers}

The workplace provides central access to employees, making it an ideal venue for HIV education and prevention programs targeting the labor force. Although workplace AIDS prevention programs for teachers are limited in the literature, some work is now being undertaken in this area. UNESCO and the 


\section{Hgrizons}

ILO have been spearheading policies to guide workplace activities in the education sector, highlighting that HIV-positive teachers can continue to be productive for many years to come (UNESCO and ILO 2006). The American Federation of Teachers' (AFT) Africa AIDS Campaign has been active in several countries since its program launch in 2001, partnering with national teachers' unions to provide schoolbased peer education programs for teachers as well as counseling and treatment to those who are sick. In Zimbabwe, AFT partnered with the Zimbabwe Teachers Association (ZIMTA) to spread HIV awareness and prevention through a multi-faceted communications campaign. Examples of the many communication strategies used in the campaign include the establishment of an AIDS hotline at ZIMTA offices throughout the country, the development of HIV educational materials focusing on lifestyle change for teachers and principals, and the revision and reinforcement of HIV management and workplace policies (kubatana.net).

In South Africa, AFT collaborated with four South African teachers' unions to launch "Prevention, Care, and Treatment Access for South African Educators" in 2005. The program sought to train 7,500 peer educators in three South African provinces with the highest incidence of HIV among teachers. The goal of the trainings was to prevent HIV transmission, to increase access to counseling, testing, and treatment, and to promote the development of workplace policies on HIV. The intervention also provided ARV treatment to 2,300 teachers and their spouses (McElligot 2005).

The AFT's Africa AIDS Campaign has been active in Kenya as well. In 2005, the Kenyan National Union of Teachers (KNUT) and the AFT implemented a two-year project using peer education designed to reduce teachers' vulnerability to HIV, to protect HIV-positive teachers from discrimination, and to provide sick leave benefits and healthcare to those teachers living with HIV. An informal assessment of the program found that teachers participating in the intervention felt more comfortable discussing HIV both in school and in the community as well as less fear and discrimination toward people living with HIV (AFT 2005).

Several additional NGOs have also commenced HIV prevention programming targeting Kenyan teachers. In 2001, the World Health Organization, Education International, and Education Development Center, Inc. co-sponsored the extensive "Teacher Training Program to Prevent HIV Infection and Related Discrimination" in 17 countries primarily in sub-Saharan Africa. Among the three goals of the intervention was to provide teachers with the knowledge and skills necessary to prevent HIV infection and to educate fellow teachers. Working directly through national teachers' unions, teachers were identified and trained to conduct skills-based, participatory learning exercises with their peers. An impact evaluation of the program found an increase in teachers' knowledge of HIV prevention and increased confidence in ability to teach about HIV and AIDS using participatory learning methods in the classroom among the more than 130,000 teachers trained from over 22,000 schools (Pevzner 2005).

Another HIV education program targeting Kenyan teachers was the Primary School Action for Better Health, implemented by The Centre for British Teachers from 2005-2006. This program delivered training to teachers from nearly 5,000 schools and included knowledge about HIV for teachers as well as strategies for including the topic in their curriculum. A unique feature of the intervention was the acknowledgment that teachers are not neutral carriers of HIV information and are influenced by their own beliefs and personal circumstances. Therefore, the program sought to complement its training by providing teachers with community support and directly addressing their concerns about delivering HIV messages in the classroom. The evaluation found significant positive effects on pupils, although changes in teachers' knowledge, attitudes, and behaviors were not measured (Brouillard-Coyle et al. 2006). 
The Kenyan Network of Positive Teachers (KENEPOTE) was formed in January 2003 by two HIVpositive teachers who wanted to shed light on the stigma and discrimination they faced from students' parents and fellow colleagues. KENEPOTE has since become a well-respected agent of change in the community as members bravely demonstrate that people living with HIV are no different than anyone else. Since its inception, the network has grown to over 3,000 members (UNESCO and EI-EFAIDS 2006).

\section{Education Sector Policies on HIV in Kenya}

In addition to programming, Kenya has been in the vanguard of developing and supporting various teacher training policies. In 2004, the government established the Education Sector Policy on HIV and AIDS (Republic of Kenya/Ministry of Education 2004), a comprehensive guideline of policies and procedures for HIV prevention, care, and support for teachers and pupils, which are in accordance with workplace policy recommendations set forth by the ILO and UNESCO. Furthermore, the Kenyan government has established an AIDS Control Unit within the Teacher Service Commission, the employer of teachers in Kenya, further demonstrating the commitment to combating AIDS in the education sector. In addition, the MOE has made HIV testing available to teachers at its headquarters.

In 2005, MOE published the "Kenya Education Sector Support Program," a five-year strategic framework for the national education sector. The report includes several goals and objectives relating to HIV among teachers, including in-service trainings on AIDS prevention, care, and support, as well as a commitment to implementing the Education Sector Policy on HIV and AIDS, and a strengthening of the Teachers Living with HIV network.

Despite these efforts, a 2006 survey by Education International, in coordination with the Kenyan National Union of Teachers (KNUT), found that among the 16,800 trainee teachers currently in teachers college, none had ever received any HIV training. Furthermore, in both primary and secondary schools, no teachers had received any HIV training from the state. Clearly, much work remains to be done.

An analysis of the impact of HIV on the primary school budget in Zambia documents that the disease will have cost as much as $\$ 41.2$ million by 2010 , to cover salaries paid to teachers absent because of AIDSrelated illnesses ( 71 percent), training of additional teachers ( 22 percent), and funeral costs ( 7 percent; Grassly et al. 2003). These are funds that could solve other problems were infection rates among teachers lowered.

Many HIV interventions rely on teachers to deliver vital prevention messages to their students, but few actively target teachers as direct beneficiaries even though the teachers themselves are at risk of HIV infection. The importance of an active response directed at teachers becomes more urgent when their influence as community leaders is considered. This report presents the findings of an evaluation of the Teachers Matter intervention, a school-based, workplace HIV prevention program targeting teachers in primary and secondary schools in Kenya. 


\section{Hgrizons}

\section{Methods and Study Sample}

\section{Research Questions}

The purpose of this research was to test an HIV risk-reduction model for primary and secondary school teachers, to increase the proportion that seek voluntary testing and counseling (VCT), and to assist those living with HIV to identify resources that could help them. The intervention addressed various worksite and non-worksite issues that affect HIV among teachers. The research questions tested were as follows:

1. Will a work-based program targeting teachers improve their knowledge, attitudes, and behaviors related to HIV?

2. Will the proposed intervention reduce the level of HIV-related stigma among teachers?

3. Will the proposed intervention increase the proportion of teachers who seek VCT?

4. Will schools that participate in the program be better able to develop internal coping mechanisms to deal with HIV in their teaching ranks?

5. What is the optimum manner of delivery of the intervention that would be most effective in achieving the above outcomes?

6. How can the intervention be improved and how can it be sustained locally?

\section{Study Methods}

\section{Study design}

In order to assess the impact of Teachers Matter, a quasi-experimental study design was employed. Quantitative and qualitative data were collected from schools in two intervention districts (Thika and Kwale) and schools in two comparison districts (Kiambu and Kilifi) in the Central and Coast provinces of Kenya.

\section{Data collection}

Quantitative surveys: Baseline survey data were collected in intervention and comparison schools prior to implementation of the intervention, and follow-up data were collected one year later. Both the baseline and follow-up surveys were administered in the same 120 schools. The study included urban and rural schools. The baseline was conducted in October 2004 and the follow up in March 2007.

Data were gathered using an anonymous, pre-tested, self-administered questionnaire in English. Most questions were multiple-choice. Interviewers received a two-day training and the same team that administered the baseline survey administered the follow-up survey. To minimize participant discomfort, school management was treated the same as other teachers during data collection, and were asked to sit in the classroom and complete the questionnaire like other teachers.

Focus group discussions: Before commencement of the intervention, focus group discussions (FGDs) were conducted in both the intervention and comparison schools to inform the content of the study. During the baseline, four FGDs were conducted with teachers and two FGDs were conducted with head teachers in both intervention and comparison schools. After the intervention, six FGDs were conducted 
with teachers in the intervention schools, and four with peer educators, in order to obtain their opinions on how the intervention went.

\section{Data analysis}

Baseline and follow-up survey results were analyzed by intervention versus comparison schools. Bivariate analysis was employed to assess preliminary associations between the exposure variable and the outcomes of interest. Multivariate analysis was conducted to assess the associations between the intervention and the desired outcomes by applying logistic regression to the follow-up data in the intervention sites. Specifically, logistic regression analysis compared the outcomes among teachers who participated in the intervention versus those who did not. The measure of association was the odds ratio. Outcome variables were dichotomized at the mean, or at appropriate quartiles. The analysis controlled for gender, age, level of teacher training, and location of the school (urban vs. rural) of the respondent. The results of the multivariate analysis are presented in Appendix I. Data were analyzed using STATA v.9.0 and SPSS v. 15.0

Qualitative data were transcribed and the transcripts were reviewed by the research team who determined key themes for coding and interpretation of study findings. The transcripts for all the FGDs were then analyzed using the qualitative analysis software NUD*IST.

\section{Ethical considerations}

The study was reviewed and received approval from Horizons/Population Council's ethical review process and Kenya's National Council for Science and Technology. Approval was also obtained from district gatekeepers and the head teachers in the participating schools. No school refused to participate in the intervention, although 17 participating teachers refused to take the follow-up survey.

\section{Study Sample}

After excluding 56 teachers who had been exposed to a similar intervention sponsored by AFT/KNUT, a total of 1,237 interviews at baseline and 1,307 interviews at follow up with teachers in four districts were retained for analysis. The survey sample was approximately evenly split between intervention and comparison schools during both rounds. Data included for analysis are only from those questions that were answered; unanswered questions were omitted and classified as "missing values." Such exclusions will only be footnoted if more than 5 percent of the responses were omitted from analysis.

Table 1 provides details of the socioeconomic and demographic status of respondents in the intervention and comparison groups at baseline and follow up. Teachers from the intervention and comparison groups at baseline and follow up did not differ significantly in terms of key demographic indicators. Overall, female teachers made up slightly more than half of the population. On average, teachers were 38 years old and about three-fourths were currently married. A third of the respondents in the intervention group taught in urban schools. Almost two-thirds of the total sample taught in primary schools. A fourth of the respondents had received graduate-level teacher training, about 18 percent had received their university 


\section{Hgrizons}

diploma, and over half of both comparison and intervention groups had been certified to teach at primary schools (level of teacher training P1-P4).

Analysis was done to compare intervention and comparison schools during the baseline, and also during the follow up. There were no statistically significant differences between intervention and comparison groups during baseline with regards to the variables presented in Table 1. Neither were there any between intervention and comparison groups during follow up. Thus both intervention and comparison school teachers are largely comparable with regards to basic demographic characteristics.

Table 1 Socioeconomic and demographic characteristics of teachers at baseline and follow up

\begin{tabular}{|c|c|c|c|c|c|c|}
\hline & \multicolumn{3}{|c|}{ Intervention } & \multicolumn{3}{|c|}{ Comparison } \\
\hline & $\begin{array}{c}\text { Baseline } \\
\mathrm{n}=572 \\
\%\end{array}$ & $\begin{array}{c}\text { Follow up } \\
n=622 \\
\%\end{array}$ & $\mathbf{p}$ & $\begin{array}{c}\text { Baseline } \\
n=665 \\
\%\end{array}$ & $\begin{array}{c}\text { Follow up } \\
n=685 \\
\%\end{array}$ & p \\
\hline $\operatorname{Sex}(\%)$ & & & ns & & & ns \\
\hline Male & 51 & 48 & & 48 & 48 & \\
\hline Female & 49 & 52 & & 52 & 52 & \\
\hline Age (\%) & & & ns & & & ns \\
\hline Under 30 & 13 & 15 & & 12 & 13 & \\
\hline 30-39 & 44 & 40 & & 49 & 45 & \\
\hline $40-49$ & 27 & 30 & & 28 & 30 & \\
\hline $50+$ & 16 & 15 & & 11 & 11 & \\
\hline Marital status (\%) & & & ns & & & ns \\
\hline Never married & 14 & 17 & & 16 & 16 & \\
\hline Currently married & 79 & 76 & & 78 & 75 & \\
\hline Other & 6 & 7 & & 6 & 8 & \\
\hline School location (\%) & & & ns & & & ns \\
\hline Urban & 27 & 26 & & 17 & 16 & \\
\hline Rural & 73 & 74 & & 83 & 84 & \\
\hline Highest level training (\%) & & & ns & & & ns \\
\hline P1-4/other & 58 & 56 & & 56 & 58 & \\
\hline S1/diploma & 18 & 18 & & 18 & 16 & \\
\hline Graduate & 25 & 26 & & 26 & 26 & \\
\hline School level taught (\%) & & & ns & & & $\mathrm{ns}^{\wedge}$ \\
\hline Primary & 64 & 64 & & 62 & 65 & \\
\hline Secondary & 36 & 36 & & 38 & 35 & \\
\hline
\end{tabular}

$\wedge 5.5$ percent missing values 


\section{Description of the Intervention}

\section{Theoretical Framework}

The intervention tested in this research was a peer education workplace program named Teachers Matter. It drew from two behavior change theories: The Transtheoretical Model for Individual Behavior Change and the Theory of Gender and Power.

Developed by Prochaska et al (1992), the Transtheoretical Model is based on the belief that behavior change does not happen in one overt step, but may be a process that involves many small steps. Individuals can progress along the behavior change continuum systematically, step by step; or, they can relapse and begin again; or they can skip certain steps (Peterson and DiClemente 2000). Behavior change programs that recognize these potential responses can intervene at the appropriate stage. In addition, factors that may not have a direct impact on behavior change, per se, may have implications earlier in the change process. Teachers Matter used this theory to refine the intervention manual and to address the various steps to behavior change by encouraging teachers to take appropriate steps such as talking to others, assessing attitudes, seeking information, and adopting healthy behaviors.

The Theory of Gender and Power posits that women have difficulties seeking self-protection from HIV because of gender-based power imbalances. Their efforts in engaging in safer sex are often influenced by their feelings about their partners, socialization of women as sexually passive, regulation as to how women should express their sexuality, and econo-power factors. In a country like Kenya, where marriage and children are still important social achievements, women may strive to stay in a risky relationship to avoid the social costs of being unmarried and childless. Therefore the intervention included a strong gender component such as incorporating cultural values, gender dynamics, and attitudes that may leave one vulnerable to HIV as a result of such norms.

\section{Program Implementation}

Teachers Matter was implemented in 120 schools in Thika and Kwale districts. However, the evaluation was conducted in only 60 of these schools; the other 60 received the intervention but were not part of the evaluation.

A total of 60 schools in Kiambu and Kilifi districts served as comparison schools, and participated in both the baseline and follow-up survey. Once the evaluation was over, they also received the full array of Teachers Matter print materials (i.e., brochures, calendars, and workplace policy booklets). Head teachers from these schools also participated in a one-day sensitization meeting so that they could explain the program to their employees. Thus collectively Teachers Matter reached 180 schools with some information about HIV, impacting about 2,700 teachers. The intervention cost approximately $\$ 42,500$ which covered preparation, printing and distribution of behavior change communication (BCC) materials, training of the peer educators (including materials, transport and accommodation), sensitization of headteachers, and availing mobile VCT services. This translates into roughly $\$ 16$ per teacher reached. 


\section{Hgrizons}

\section{Peer education training and preparation}

Teachers Matter was a peer-led education program, guided by a 10-unit interactive and audience-driven manual. The manual provided factual information about how HIV is transmitted, risk reduction strategies, and HIV testing, as well as treatment, care, and support for people living with HIV. It also discussed home-based care and provided participants with HIV resources in their communities. In addition, the manual addressed social and cultural dimensions that may deter individuals from adopting risk reduction behavior even if they have the information. For example, topics such as sexuality, relationships, family values, and self-esteem were presented. Informed by the theories discussed above, the manual used experiential and adult-oriented teaching methodologies, and was largely comprised of small group discussions and interactive exercises. Each section ended with a take-home message. Every unit was designed with simple instructions so any peer educator could lead the discussion and convey the key messages.

Head teachers from intervention schools received a two-day sensitization training about the Teachers Matter project, in order to seek their input and support. One teacher from each school was then selected by their colleagues, with consultation from the head teacher, to serve as the peer educator for that school. All schools approached for the intervention were cooperative and provided a peer educator for the training. At the end of the training, all peer educators received a certificate recognizing their participation.

Before the intervention, the 120 peer educators received a one-week training on how to use the manual. During the training, they practiced through group sessions, interactive activities, skits, and games. They received in-depth information about HIV, ranging from the origins of HIV to AIDS treatment. They opened condoms, stretched and twisted them, and filled them with water to test leakage. Many saw both a male and female condom for the first time. They were also offered VCT by a mobile VCT team that availed services throughout the training. About 33 percent of the peer educators took an HIV test for the first time.

A major component of the training was the involvement of KENEPOTE. KENEPOTE members joined the training meetings and talked about the challenges of HIV-positive teachers. They gave concrete suggestions regarding how the school management could support HIV-positive colleagues, with an emphasis toward stigma reduction. Because of their enthusiasm, dedication, and openness, KENEPOTE members normally left most teachers feeling more comfortable dealing with HIV-positive colleagues.

Prior to departure to their respective schools, peer educators developed a nine-month work plan and identified resources needed to execute the project in their school. Program implementation began immediately. Throughout the intervention, peer educators were supported by quarterly visits from the Teachers Matter study monitor, who assisted them with troubleshooting and also supplied them with education materials and brochures. Each peer educator completed a peer educator diary on which s/he recorded activities for each session and documented any issues that may have arisen. The Teachers Matter monitor reviewed the diaries during his visits. Peer educators also received refresher training midway through the intervention. 


\section{Program activities}

Peer educators were given the freedom to schedule the intervention to meet the needs of their respective schools. Most Teachers Matter meetings were held on a weekly basis, and lasted from 30 to 90 minutes. While some schools appointed a set time to meet each week, either after working hours or during lunch, others were more flexible and programmed as they went along. Most schools reported having covered the majority of the manual by the conclusion of the nine-month program.

During their training, peer educators were encouraged to identify a colleague in their school who could assist them as their co-peer educator. Many peers did so, and found the support to be invaluable, whether to fill in for the peer educator if there was a scheduling conflict, to provide expertise, or to lead a meeting that the main peer educator might not have felt comfortable with. As one peer educator explained:

I trained a [female teacher] given that our staff also has female teachers and there are some areas that in the manual if a female teacher is to explain, it stands a better chance of being understood properly. So this teacher was able to talk to female teachers on some areas that I found hard for me to discuss.

Secondary school teacher, Kwale

Several teachers echoed this sentiment and suggested that for future programs, two teachers from each school be selected and trained to lead the project, so they can share the work and complement one another.

Head teachers and school management were also encouraged to be involved in the project. At some schools, management was very supportive of the program and allowed teachers time to meet and sometimes provided refreshments or supplies as needed.

The program fared on well with the help of the head teacher. He treated it as a school program and everybody had to attend....

Secondary school teacher, Thika

At others times, head teachers were not involved with the project, making the peer educators feel unsupported. As another peer educator commented:

...I had to take the lead when most of the time the administrator is there.... Instead of him being a role model, I was the one who is supposed to go ahead and invite the other teachers to come, thus shouldering the responsibility.

Secondary school teacher, Kwale

Indeed, although it was important that the peer educators took ownership of the program, head teachers and school management involvement was invaluable in assuring program attendance and participation by other teachers.

Peer educators had been trained to conduct the sessions in an interactive and adult-centered manner. Because of the friendly nature of the manual, teachers took to it immediately. Discussions frequently erupted spontaneously addressing topics such as the availability of condoms in the staff room, HIV testing, stigma, sexual practices, domestic violence, and alcohol use. Some teachers asked whether they 


\section{Hgrizons}

could bring their partners to participate in the discussions. Schools were given the leeway to respond to their issues as they arose.

Support materials: All peer educators received an education kit that contained education brochures, a penis model, samples of both male and female condoms, samples of ARVs, and other educational materials. Because Teachers Matter was commencing activities just as the MOE was starting distribution of its Education Sector Workplace Policy on HIV and AIDS, copies of the policy were included in the project as well. The project also adopted existing print materials and brochures to make them teacherspecific. A number of brochures were prepared:

- What Teachers Need to Know About Sexually Transmitted Diseases (STDs)

- Talking about Condoms

- What Teachers Need to Know About Condoms

- $\quad$ Talking about Voluntary Counseling and Testing (VCT)

- Talking about Antiretroviral Therapy (ART)

- Positive Living with HIV

- Care and Support for People Living with HIV: The Role of Teachers

- ARVs: What Teachers Need to Know

- Understanding Opportunistic Infections: What Teachers Need to Know

- ARVs: Managing Side Effects

In addition, two 3-leaf calendars for teachers were prepared. The 2006 calendar, distributed at the start of the intervention, addressed three themes: HIV testing, stigma, and access to treatment. The 2007 calendar, distributed at the end of the intervention, portrayed photographs of teachers who had been tested for HIV as part of the project, stressing the importance of HIV testing and counseling for teachers and their partners. Many teachers were excited to see themselves in a calendar and some who had not been tested were heard to say they would get tested so that they could be in next year's calendar.

An important resource for the peer educator was the peer educators' bag. A multi-compartment shoulder case, it was designed and produced by the Kenya AIDS and Drug Alliance (KADA), a group for people living with HIV. The bag was made of sturdy materials enabling use in inclement weather. It contained see-through pouches where the peer educator could easily access relevant supplies such as the penis model, brochure, and samples of ARVs. KADA was also contracted to supply penis models for the project.

Throughout the intervention, the Teachers Matter study monitor cut out relevant newspaper clippings and provided any other materials that could assist teachers. He helped teachers in each school develop a resource corner in the staff room where materials could be displayed. The materials were distributed strategically over the course of the intervention, to avoid inundating teachers, and to introduce materials as topics were being introduced. This information corner was very well-received. As one peer educator noted:

The establishment of the information corner has been very helpful because even if the teachers miss a session, they come to the information corner and they are able to access some of the information that is very crucial. 
Peer educators were especially enthusiastic about the BCC materials provided. Many found them to be useful teaching aids that often complemented the lessons taught:

I think for my case the brochures were very useful. Sometimes when we couldn't hold discussion sessions, teachers could be given them to go through on their own. Then the next day when we met, I would clarify what was not clear, and we would discuss any inquiries that they had on them.

Secondary school teacher, Kwale

Participating teachers also found the materials useful:

[The brochures] now serve as reference material, so that even later, we refer to it. If say now, I came across a question involving positive living ... I will refer to this brochure on positive living; refer to it, get feedback, and pass it over. So it is a reference material.

Primary school teacher, Thika

Teachers noted however that while a penis model was available for demonstrating the use of male condoms, there was no pelvic model for demonstrating the female condom. Many female teachers noted this issue and felt that one should have been provided.

Additional activities: Teachers organized themselves to participate in other activities throughout the intervention. For example, during World AIDS Day, teachers in Kwale and Thika organized several large-scale events to draw attention to the subject and involve the community. In Kwale, the day's program included songs and dances by women's groups and traditional dancers, poems read by members of the KENEPOTE, and speeches by peer educators.

In addition, teachers organized an inter-school football match entitled "The Teachers Matter Tournament." The nine-team tournament culminated in the final round on World AIDS Day to convey the message that "AIDS is there, it has not gone." Voluntary counseling and testing services were made available to anyone who chose to get counseled or tested throughout the day. Teachers in other schools planted trees. At all schools, innovation was encouraged and teachers were free to adapt the intervention to their situation.

Thika School for the Visually Impaired was one of the schools included in the intervention. Written materials provided to this school were converted into Braille, the first time any such information had been availed in this format. Teachers at this school were quite enthusiastic in their participation.

\section{Challenges}

Although the program was very well-received by the teachers, there were some challenges in program implementation. Participating teachers and peer educators alike complained of the meetings taking up valuable time during their busy days. Meetings were best attended when scheduled during lunch hour, instead of after school when many were in a rush to go home and attend to their families and other responsibilities. Peer educators especially felt this constraint: 


\section{Hgrizons}

... Given the workload we had ... the additional responsibility was quite an issue. I feel if my workload can be made easier, then the implementation of this program can be made more effective.

Secondary school teacher, Kwale

Another challenge was the heterogeneity of the audience. Because the age range of participating teachers was quite large, it could be challenging for peer educators to teach lessons to a mixed age group. For example, some younger peer educators had a hard time delivering sensitive messages of condom use or safe sex to older teachers. As a peer educator explained:

In my school, I am the youngest. So when I introduced the Teachers Matter there, the teachers were negative about it. They were saying, "How can you tell us these things and you are our son?" But as we continued they became receptive of the program.

Secondary school teacher, Kwale

Attrition of both peer educators and teachers was another issue, as transfers between schools are frequent. At times, the program was preemptively terminated because the peer educator was moved to another school. As one peer educator recommended:

Peer educators as teachers are faced with the inevitable transfers. And we might be taken to a school where there is already a peer educator, leaving the other school without any peer educator. So, I request that peer educators can be given a longer time in the current school...to make the program solid in those schools.

Secondary school teacher, Kwale

Some teachers requested incentives or financial compensation to continue their participation, a common practice in Kenya called a "sitting allowance":

Ifeel the teacher should have received a motivation, given that we had to be here for the program. Because as much as the program is there for us, we need to be motivated in one way or the other, like giving us refreshments. If this component can be factored in the program then it will be more effective. If we can be issued with certificates of participation, that can be very nice.

Another peer educator confirmed:

Primary school teacher, Kwale

Teachers wanted a motivation, in form of an incentive for keeping them in the discussion for those hours. So, that component of complaints from the teachers is what I didn't like, and the hard part of explaining that there are no cash handouts or material incentives, but the knowledge they were gaining was better than any incentives.

Secondary school teacher, Kwale

In some cases, teachers, including peer educators, were reluctant to participate fully in the intervention, lest it be construed that they had a "reason" to be so interested. Such peer educators would therefore conduct sessions nonchalantly, to distance themselves from the intervention. Sometimes disinterested teachers would sit on the side doing other work, while the Teachers Matter sessions were going on. Over time however, the majority of teachers joined in the group. As one of the peer educators later explained during a session on domestic violence, some teachers sitting on the sidelines had been doing so because 
they were personally experiencing the problems being addressed, and the session had therefore been too painful.

Another challenge was the difficulty in separating teachers from their roles as gatekeepers of information. Although it was stressed time and again that the information presented was for the teachers themselves, their instincts were to see it as a lesson to be passed on to their students or to the community. While teachers who are well educated about HIV issues are undoubtedly a benefit for the whole community, ensuring that lessons learned resonated in the teachers' personal lives was a complex issue.

The implementation of the project coincided with a turbulent change in the funding environment, leading to sharp financial cutbacks for operations research. This primarily meant seeking funds afresh for the intervention, and the outcome was a 17-month lag between the baseline survey and implementation of the intervention. In addition, because such a teacher-centered intervention was a relatively new undertaking in Kenya, there was also limited experience and personnel to draw from. 


\section{Results}

\section{Exposure to Teachers Matter}

The 622 respondents in the intervention schools were asked whether they had heard of Teachers Matter, whether they had participated in it, whether they had taken any specific actions as a result of being exposed (e.g., sought VCT), and whether they would recommend it be continued. The results, presented on Table 2, are based on all 622 respondents, in order to assess the aggregate levels of exposure to the intervention. The data show that 92 percent of all teachers in the intervention site had heard of Teachers Matter, 80 percent had participated, 71 percent had taken some type of action, and 75 percent would recommend that it continue. Exposure and interaction with Teachers Matter was the same among the various demographic groupings, but primary school teachers were more likely than secondary school teachers to have participated in the intervention, to have taken action, and to say that they would recommend that the program continue. Similarly, older teachers were also more likely to have participated in the intervention than younger teachers, to have taken action as a result, and to recommend continuation. Of the teachers who participated in Teachers Matter, 12 percent were peer educators.

Table 2 Exposure to Teachers Matter in the intervention schools at follow up, by selected respondent characteristics

\begin{tabular}{|c|c|c|c|c|c|c|c|c|}
\hline & \multicolumn{2}{|c|}{$\begin{array}{c}\text { Heard of } \\
\text { Teachers } \\
\text { Matter } \\
\mathbf{n}=622\end{array}$} & \multicolumn{2}{|c|}{$\begin{array}{c}\text { Participated in } \\
\text { Teachers } \\
\text { Matter } \\
n=622\end{array}$} & \multicolumn{2}{|c|}{$\begin{array}{c}\text { Took } \\
\text { action } \\
n=622\end{array}$} & \multicolumn{2}{|c|}{$\begin{array}{c}\text { Recommend } \\
\text { intervention } \\
\text { continue } \\
n=622\end{array}$} \\
\hline & $\%$ & $\mathbf{p}$ & $\%$ & $\mathbf{p}$ & $\%$ & p & $\%$ & $\mathbf{p}$ \\
\hline Gender & & ns & & ns & & ns & & ns \\
\hline Male & 92 & & 83 & & 73 & & 76 & \\
\hline Female & 91 & & 78 & & 70 & & 75 & \\
\hline Age & & ns & & 0.013 & & 0.04 & & 0.04 \\
\hline Mean or below & 90 & & 76 & & 68 & & 72 & \\
\hline Above mean & 93 & & 85 & & 75 & & 79 & \\
\hline School location & & ns & & ns & & ns & & 0.01 \\
\hline Urban & 88 & & 75 & & 65 & & 67 & \\
\hline Rural & 92 & & 82 & & 73 & & 78 & \\
\hline Level of school taught & & 0.02 & & $<.001$ & & $<.001$ & & $<.001$ \\
\hline Primary & 93 & & 86 & & 78 & & 83 & \\
\hline Secondary & 88 & & 72 & & 60 & & 64 & \\
\hline Among all & 92 & & 80 & & 71 & & 75 & \\
\hline
\end{tabular}


Participating teachers $(n=500)$ listed several kinds of information that they obtained from the project, as illustrated in Figure 1. About 80 percent or more of those respondents reported acquiring basic facts about HIV, as well as information about male condoms, where to get tested for HIV, antiretroviral therapy, and positive living with HIV.

Figure 1 Information obtained from Teachers Matter $(n=500)$

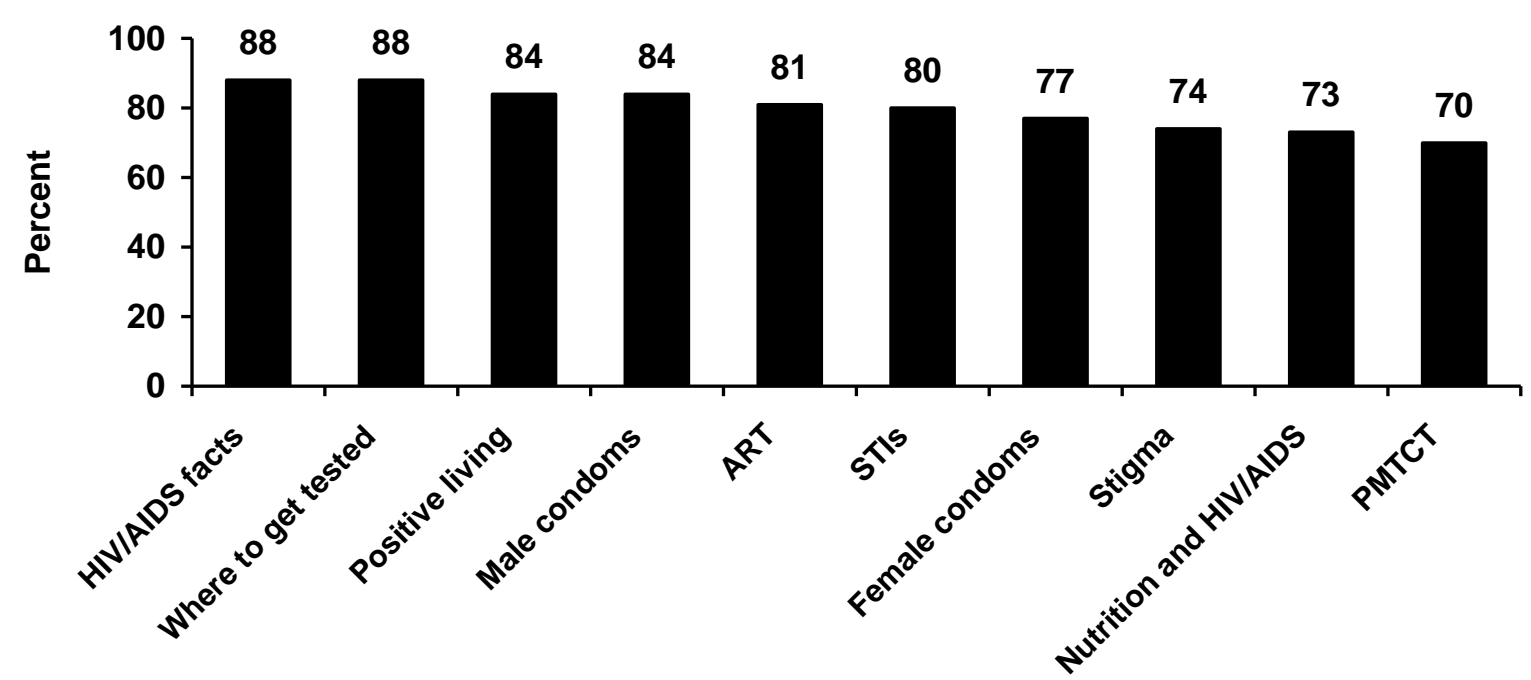

Teachers were also asked in what ways the program had benefited them and the answers are presented in Figure 2. In addition to information obtained from the project previously listed, the majority of teachers also thought the intervention successfully encouraged behavior change, enabled more openness among teachers about HIV, improved the relationship between teachers and school management regarding HIV, and decreased the level of stigma among teachers. 


\section{Hgrizons}

Figure 2 Effect of Teachers Matter on lives of participating teachers $(n=500)$

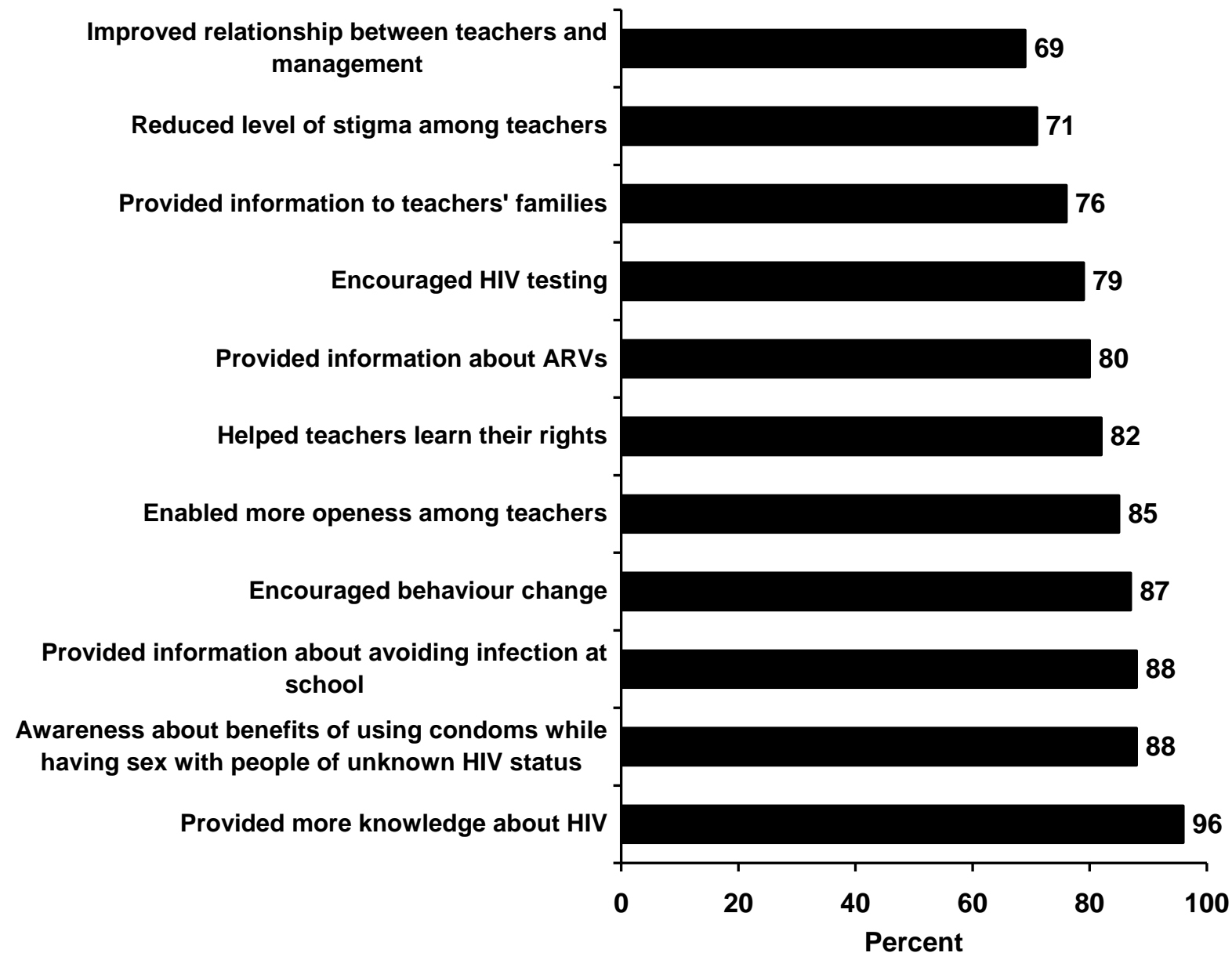

About 90 percent of those teachers who participated in the Teachers Matter program took further action related to HIV as a result of what they learned from the project. Figure 3 shows the most popular examples of action taken. 
Figure 3 Actions taken related to HIV by participating teachers $(n=442)$

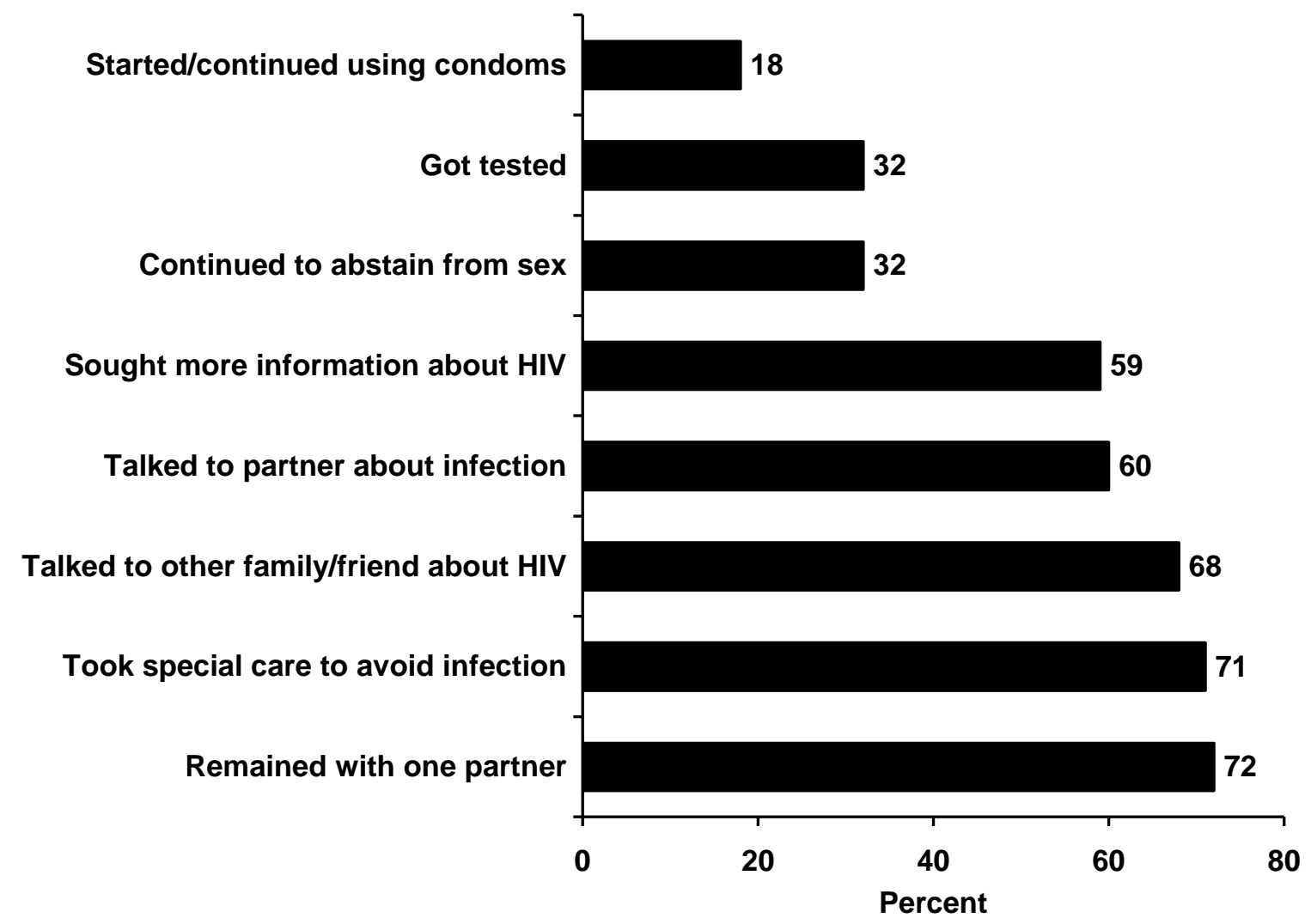

\section{Effects of Teachers Matter Intervention on Selected Outcome Measures ${ }^{3}$}

An assessment of the baseline and follow-up surveys of the intervention and comparison groups allows for a measurement of change in teachers' knowledge, attitudes, and behaviors related to HIV. It is important to note, however, that the Teachers Matter project was not the only agent of change attempting to influence HIV knowledge, attitudes, and practices in Kenya. For example, the country is in the middle of a vigorous campaign called "Total War Against AIDS," which is being led by the country's President himself. HIV is widely discussed in the media, public meetings, churches, and other venues. Politicians and many famous personalities have publicly been tested for HIV, attracting large media coverage. And HIV is part of the education curriculum, with teachers expected to infuse HIV across all subjects in schools as they teach students. However, it was anticipated that the teachers exposed to the intervention would exhibit greater changes in the outcomes assessed than their unexposed counterparts.

\footnotetext{
${ }^{3}$ More detailed results of logistic regression are further found in Appendix I.
} 


\section{Hgrizons}

\section{Work environment}

Coping with HIV at the Workplace: The defining feature of the Teachers Matter project was its design as a workplace intervention for teachers. As with most workplace interventions, a key objective was to create a supportive environment allowing teachers to effectively cope with HIV. Table 4 shows a significant difference in teachers' opinions of how proficient school management and other teachers had become in coping with HIV issues. When the follow-up sample was asked how effective school management had become in coping with HIV issues at school in the last year, 28 percent of the intervention school teachers said there had been a "great improvement," compared to 19 percent of the comparison school teachers ( $\mathrm{p}<.0001)$. Similarly, 35 percent of the teachers in the intervention schools said their colleagues had shown "great improvement" in coping with HIV issues in school, with only 26 percent of teachers concurring in the comparison schools $(\mathrm{p}<.0001)$. Thus there was greater improvement in collective self-efficacy and coping capacity demonstrated in the intervention schools.

\section{Table 4 Perceived effectiveness of school management and colleagues to cope with HIV issues at the workplace, follow-up sample}

\begin{tabular}{|c|c|c|c|}
\hline & $\begin{array}{c}\text { Intervention } \\
\mathbf{n}=622 \\
\%\end{array}$ & $\begin{array}{c}\text { Comparison } \\
\text { n = 695 } \\
\%\end{array}$ & $\mathbf{p}$ \\
\hline $\begin{array}{l}\text { Improvement of management's effectiveness to cope with } \\
\text { HIV/AIDS in school (compared to one year ago) }\end{array}$ & & & $<.001$ \\
\hline Great improvement & 28 & 19 & \\
\hline Some improvement & 62 & 62 & \\
\hline No improvement / worse & 10 & 19 & \\
\hline $\begin{array}{l}\text { Improvement of teachers' effectiveness to cope with } \\
\text { HIV/AIDS in school (compared to one year ago) }\end{array}$ & & & $<.001$ \\
\hline Great improvement & 35 & 26 & \\
\hline Some improvement & 60 & 62 & \\
\hline No improvement / worse & 5 & 12 & \\
\hline
\end{tabular}

$\wedge<5$ percent missing values

Teachers and peer educators expressed enhanced ability to cope with colleagues infected with HIV or AIDS at the workplace. When asked how the teachers would treat an HIV-positive colleague, responses were very supportive:

Previously, one would be stuck not knowing what to tell or how to treat the HIV-infected person. But after the introduction of Teachers Matter, you would not miss a word of encouragement and giving proper examples to such a person.

Primary school teacher, Thika

Personally, I can say there is a change in school environment. When you pass this knowledge to the people, although you may not notice it, but with time, something happens. There is a person 
within our school who got sick and, in fact, everybody knew or suspected the disease and they tried to talk to him concerning the ARVs.

Primary school teacher, Kwale

After controlling for gender, age, level of teacher training, and urban-rural school location in multivariate analysis, attendance at Teachers Matter meetings was significantly associated with an increasingly positive belief that teachers were able to deal with HIV issues at the workplace. Those who attended some Teachers Matter meetings were 1.7 times more likely to think that teachers could effectively cope with workplace HIV issues when compared to their unexposed counterparts (CI: 0.9-3.1), while those who attended all meetings were 3.6 times more likely to believe so (CI: 1.9-6.7; see Appendix I). Regarding the perceived ability of management to cope with workplace HIV issues, the effect was not as strong but all the same, those attending all meetings were 1.7 times more likely to believe management could cope with such issues compared to their counterparts who did not attend any (CI: 0.9-3.2; see Appendix I).

Job security and confidentiality: A vital part of any workplace HIV policy is confidentiality and nondiscriminatory hiring and firing practices. However, even after the Teachers Matter intervention, the consequences of breaching confidentiality and violating other policies remained largely unclear, in part because the current Education Sector Policy on HIV and AIDS does not provide definitive guidance on this issue. For example, teachers were asked, "As far as your school's regulations are concerned, what recourse would an HIV-positive teacher have if a fellow teacher disclosed the HIV-positive teacher's status without consent?" Over half of teachers in both comparison and intervention schools said they did not know (see Table 5). Teachers also seemed uncertain that their school management could maintain confidentiality if a teacher were to disclose his or her HIV-positive status. When asked about this, the comparison and intervention populations were fairly evenly divided, with about a fourth thinking they could maintain confidentiality, another fourth saying they could somewhat maintain confidentiality, another fourth saying they could not maintain confidentiality, and a final fourth saying they did not know whether or not they could maintain confidentiality. Thus assurance regarding HIV confidentiality did not improve significantly over time. 
Table 5 Perceptions of confidentiality and job security regarding HIV among teachers at baseline and follow up

\begin{tabular}{|c|c|c|c|c|c|c|}
\hline & \multicolumn{3}{|c|}{ Intervention } & \multicolumn{3}{|c|}{ Comparison } \\
\hline & $\begin{array}{c}\text { Baseline } \\
\mathrm{n}=572 \\
\%\end{array}$ & $\begin{array}{c}\text { Follow up } \\
\mathrm{n}=622 \\
\%\end{array}$ & $\mathbf{p}$ & $\begin{array}{c}\text { Baseline } \\
\mathrm{n}=665 \\
\%\end{array}$ & $\begin{array}{c}\text { Follow up } \\
\mathrm{n}=685 \\
\%\end{array}$ & p \\
\hline $\begin{array}{l}\text { Don't know recourse for breach of } \\
\text { confidentiality }\end{array}$ & 56 & 59 & ns & 61 & 60 & ns \\
\hline $\begin{array}{l}\text { Administrator is able to maintain } \\
\text { confidentiality }\end{array}$ & 23 & 27 & ns & 22 & 23 & ns \\
\hline \multicolumn{7}{|l|}{$\begin{array}{l}\text { What would happen if HIV-positive } \\
\text { status disclosed to employer }\end{array}$} \\
\hline Would be fired & 3 & 1 & $<.001$ & 2 & 2 & $<.001$ \\
\hline $\begin{array}{l}\text { May not be fired but would be } \\
\text { discriminated against }\end{array}$ & 37 & 29 & & 38 & 33 & \\
\hline Nothing & 35 & 48 & & 32 & 45 & \\
\hline Don't know & 25 & 21 & & 27 & 21 & \\
\hline
\end{tabular}

There was an increase in perceptions of job security and HIV as evidenced by the proportion of teachers who thought "nothing" would happen to their jobs if their employers found out they were HIV-positive, which increased from a third of respondents at baseline to nearly half at follow up. Similar findings were documented in the comparison group (see Table 5). Increases in perceived job security in both intervention and comparison groups may be attributed to widespread attention to the issue of job discrimination in the Kenyan media. Still many teachers remain apprehensive that all would not be well, and they would be discriminated against if they were HIV-positive even if they were not fired. In addition, nearly a fourth of respondents in both study sites said they did not know what would happen, while about two percent believed they would be fired. Put together, the survey suggests that at the followup survey, 51 percent of teachers in the intervention schools and 56 percent of those in the comparison schools were doubtful that all would remain the same if the employer were to find out that they were HIV-positive.

Workplace policy on HIV: An integral part of creating a HIV-supportive workplace environment is the development of a workplace policy on HIV and ensuring the policies stated are known, understood, and adhered to by all employees. In this regard, the Kenya Ministry of Education published the "Education Sector Policy on HIV and AIDS" in 2004. This document was distributed by the Ministry of Education to schools countrywide.

Teachers in this survey were asked whether they had heard about this policy, whether they had seen it, and whether they had read it. Table 6 shows that there was a significant increase in the intervention groups' knowledge and familiarity of the policy between baseline and follow up. The percentage of those in the intervention group who had heard about the policy increased from 42 percent at baseline to 61 percent at follow up ( $<$.0001). Of those, the percentage that had seen a copy of it also increased from 28 percent at baseline to 58 percent at follow up $(\mathrm{p}<.0001)$. The percentage of teachers who had heard of and/or seen a copy of the policy in the comparison group did not change significantly over time. 


\section{Table 6 Familiarity with Kenya MOE "Education Sector Policy on HIV and AIDS" among teachers at baseline and follow up}

\begin{tabular}{|c|c|c|c|c|c|c|c|c|c|c|}
\hline & \multicolumn{5}{|c|}{ Intervention } & \multicolumn{5}{|c|}{ Comparison } \\
\hline & \multicolumn{2}{|c|}{ Baseline } & \multicolumn{2}{|c|}{ Follow up } & \multirow[b]{2}{*}{$\mathbf{p}$} & \multicolumn{2}{|c|}{ Baseline } & \multicolumn{2}{|c|}{ Follow up } & \multirow[b]{2}{*}{$\mathbf{p}$} \\
\hline & $\mathbf{n}$ & $\%$ & $\mathbf{n}$ & $\%$ & & $\mathbf{n}$ & $\%$ & $\mathbf{n}$ & $\%$ & \\
\hline Heard about policy^ & 572 & 42 & 622 & 61 & $<.001$ & 665 & 40 & 685 & 39 & ns \\
\hline Seen a copy of policy ${ }^{\infty}$ & 220 & 28 & 362 & 58 & $<.001$ & 244 & 24 & 259 & 22 & ns \\
\hline Read the policy^ & - & - & 622 & 29 & & - & - & 685 & 6 & \\
\hline
\end{tabular}

${ }^{\wedge}$ Among the total sample; ${ }^{\infty}$ Among those who had heard about it

At the follow-up survey, teachers were asked if they had read the policy. Table 6 shows that of the total sample, significantly more had done so in the intervention group compared to the comparison group (29 percent vs. 6 percent, $\mathrm{p}<.001)$. These figures suggest that teachers are responsive to informing themselves of workplace policies if they are given access to them. Multivariate analysis confirms these findings: after controlling for gender, age, level of teacher training, and urban-rural school location, teachers who attended Teachers Matter meetings were significantly more likely to read the Education Sector Policy on HIV and AIDS than their unexposed counterparts. Those who attended some meetings were 2.0 times more likely to have read it (CI: 1.0-3.9); those who attended all meetings were 5.6 times more likely to have read the policy (CI: 2.8-11.2; see Appendix I).

Perceived risk of HIV infection: A final aspect of workplace HIV initiatives was to ease fears about HIV infection at the workplace. During the baseline, many teachers had expressed great anxiety about HIV transmission, for example while delivering first aid to children. They were concerned that the greater number of children now enrolled as a result of the free primary school program would include large numbers of poor HIV-positive children who had previously kept away. Therefore Teachers Matter worked to quell some of these apprehensions. After participating in the intervention, there was some improvement. For example, when asked how concerned they were about becoming infected with HIV at work, the percent that were "very concerned" decreased from 65 percent to 57 percent between baseline and follow up in the intervention group $(\mathrm{p}=0.017)$. There was no change in the comparison schools $(61$ percent during both rounds, $p=0.726$; see Table 7). Multivariate analysis suggests that the changes were too small to observe after controlling for the confounders (data not shown). All the same, teachers were appreciative of the intervention and as one explained:

Teachers Matter helped us to dispel the fear we used to have because it is only a teacher who does not know how HIV is spread that has those fears. It has helped us to know that if I handled a child who has HIV but I do not touch his blood, I cannot contract this disease. So, those fears I can say, they are not really there anymore.

Primary school teacher, Thika

Still, it is noteworthy that 57 percent of teachers remained concerned about this problem despite the intervention. During the follow-up survey, the research team asked teachers whether their schools had a first-aid kit, as recommended by the Education Sector Policy on HIV and AIDS. Less than ten percent of sites had a fully stocked one (7 percent of intervention and 11 percent of comparison schools), while 


\section{Hgrizons}

about 40 percent of sites had a partially stocked one. The fears about HIV infection among teachers may be emanating from awareness that their schools are not adequately prepared in case of learner injury or other emergency.

\section{Table 7 Perceived risk of HIV infection at work and overall among teachers at baseline} and follow up

\begin{tabular}{lccc|ccc}
\hline & \multicolumn{3}{c|}{ Intervention } & \multicolumn{3}{c}{ Comparison } \\
& $\begin{array}{c}\text { Baseline } \\
\mathbf{n}=\mathbf{5 7 2} \\
\%\end{array}$ & $\begin{array}{c}\text { Follow up } \\
\mathbf{n}=\mathbf{6 2 2} \\
\%\end{array}$ & $\mathbf{p}$ & $\begin{array}{c}\text { Baseline } \\
\mathbf{n}=\mathbf{6 6 5} \\
\%\end{array}$ & $\begin{array}{c}\text { Follow up } \\
\mathbf{n}=\mathbf{6 8 5} \\
\%\end{array}$ & $\mathbf{p}$ \\
\hline $\begin{array}{l}\text { Highly concerned about HIV } \\
\text { infection at work }\end{array}$ & 65 & 57 & 0.017 & 61 & 62 & $\mathrm{~ns}$ \\
$\begin{array}{l}\text { Low concern about HIV } \\
\text { infection overall }\end{array}$ & 39 & 47 & 0.026 & 43 & 46 & $\mathrm{~ns}$ \\
\hline
\end{tabular}

Respondents were also asked to assess their overall risk of HIV at work and at home. It was anticipated that greater understanding about HIV, and increased self-efficacy and coping abilities would help teachers assess their risk in a more informed manner. Table 7 shows that there was a significant increase in those believing they were at lower risk in the intervention schools, from 39 percent at baseline to 47 percent at follow up in the intervention group $(\mathrm{p}=0.026)$. There was no change in perceived risk at work or at home in the comparison group (43 percent at baseline vs. 46 percent at follow up, $\mathrm{p}=0.637$ ).

\section{Post-exposure prophylaxis}

Post-exposure prophylaxis (PEP) is now widely available in Kenya, and Teachers Matter provided an opportunity to inform educators about it, for use both at work and at home. Figure 4 shows that at baseline, 4 percent of the teachers in the intervention schools said they knew what PEP was; at follow up, 25 percent of teachers said they did $(\mathrm{p} \leq .0001)$. In the comparison schools, 2 percent of teachers said they knew what PEP was at baseline, which remained about the same at follow up ( 3 percent).

Greater exposure to Teachers Matter is significantly associated with higher knowledge of PEP, and each incremental exposure is associated with increased knowledge. After controlling for gender, age, level of teacher training, and urban-rural school location in multivariate analysis, those who attended some Teachers Matter meetings were 2.6 times more likely to know what PEP was than their unexposed counterparts (CI: 1.2-5.9), while those who attended all Teachers Matter meetings were 6.7 times more likely to know what PEP was (CI: 3.0-15.2; see Appendix I). 


\section{Figure 4 Percent who said they knew what PEP was, baseline and follow up}

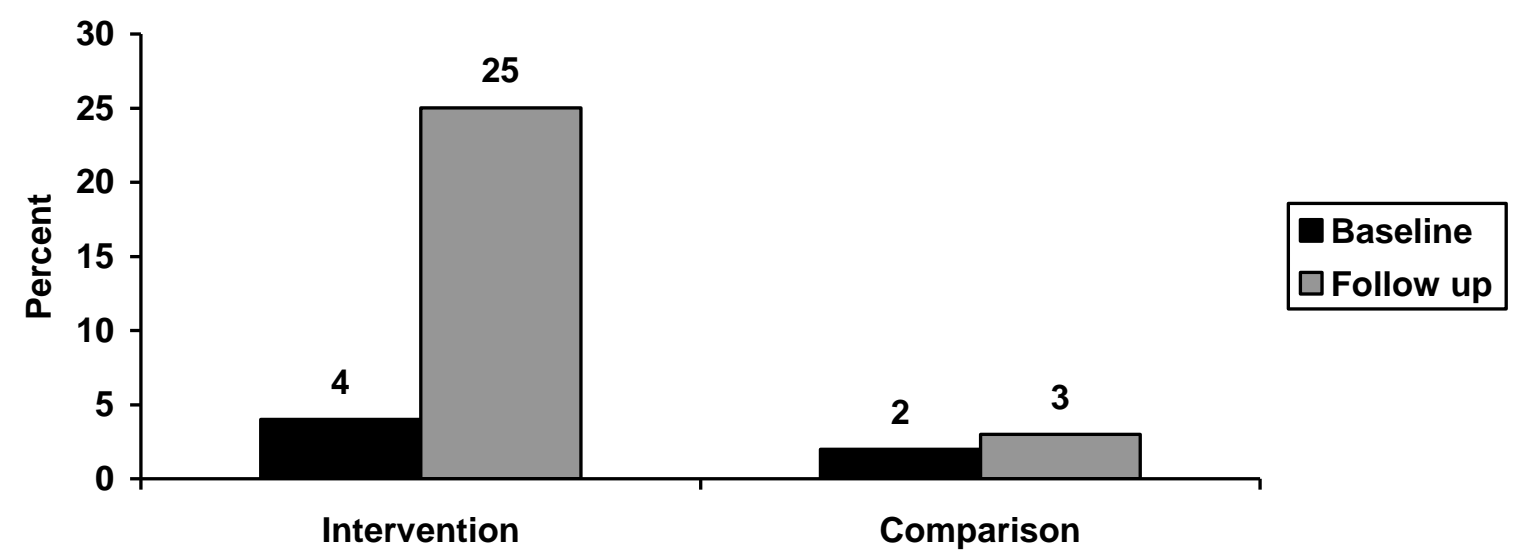

Teachers were also able to translate what they learned about PEP into action:

... On the issue of PEP, this program helped a lot. I remember sometime back when one of our students was injected by a person feared to be HIV-positive, and then teachers who were around, employing the knowledge they had got about PEP took the necessary action of taking the child to the nearest VCT center, where the child was counseled, tested, and given the drug."

Primary school teacher, Thika

\section{Attitudes toward condoms}

Male condoms: Table 8 illustrates attitudes toward male condoms among the study population at baseline and follow up. To quantify attitudes, a nine-point question was posed in the survey asking respondents to agree or disagree with varying statements about the use and acceptability of condoms (see Appendix II). Based on the participants' responses, a score was developed. Respondents were dichotomized as having favorable or unfavorable attitudes based on whether they scored above or below the mean of five favorable answers. A positive attitude toward condoms indicated more than five (>5) supportive answers. A negative attitude indicated five or fewer $(\leq 5)$ supportive answers. Bivariate analysis showed that there was a highly significant change in the intervention group between baseline and follow up, with the percent having supportive attitudes rising from 49 percent to 64 percent $(p<.0001)$. By comparison, the increase in the comparison group was not significant (52 percent to 58 percent, $\mathrm{p}=0.071$ ). 
Table 8 Attitudes toward male condoms among teachers at baseline and follow up

\begin{tabular}{|c|c|c|c|c|c|c|}
\hline & \multicolumn{3}{|c|}{ Intervention } & \multicolumn{3}{|c|}{ Comparison } \\
\hline & $\begin{array}{c}\text { Baseline } \\
\mathrm{n}=572 \\
\%\end{array}$ & $\begin{array}{c}\text { Follow up } \\
n=622 \\
\%\end{array}$ & $\mathbf{P}$ & $\begin{array}{c}\text { Baseline } \\
\mathrm{n}=665 \\
\%\end{array}$ & $\begin{array}{c}\text { Follow up } \\
n=685 \\
\%\end{array}$ & $\mathbf{p}$ \\
\hline Condom attitude \% & & & $<.001$ & & & ns \\
\hline Positive & 49 & 64 & & 52 & 58 & \\
\hline Negative & 51 & 36 & & 47 & 42 & \\
\hline Mean score (out of 9) & 5.1 & 6.1 & $<.001$ & 5.3 & 5.6 & 0.02 \\
\hline
\end{tabular}

The bivariate results were marginally supported by the multivariate analysis which showed that at the highest exposure to Teachers Matter, respondents were more likely to have positive attitudes toward condoms (OR 1.7, CI 0.9-3.1).

Peer educators were provided with condoms, and study participants preferred accessing condoms from peer educators as opposed to doing so at kiosks and other public locations, which were considered indiscrete and embarrassing. As two peer educators confirmed:

...There was a remarkable observation of behavior change as far as condom use is concerned.... Like when I had a full box of male condoms when we came back from [the peer educator training]. Within no time they had disappeared.... It was obvious they were being used....

Secondary school teacher, Kwale

I think behavior change is there, because you hear them when you are near them ask each other, "Do you have condoms? Do you have?" ... They come to me to ask for the condoms. Like the ones I came with from [peer educator training], there was not even one left. They were telling me to assist them to get more ....

Primary school teacher, Thika

Female condoms: Female condoms are also a viable way to prevent HIV infection during sex. While there were significant increases in awareness of female condoms in both the intervention and comparison groups during the study period, the change was greater in the intervention group (see Table 9). About 79 percent of the baseline respondents in the intervention schools had heard of female condoms prior to the intervention, and this had risen to 97 percent at follow up $(\mathrm{p}<.001)$. In the comparison schools, the percent who had heard of them rose from 87 percent to 93 percent $(p<.001)$. Of those who had heard of it, there was an increase in the percent who had seen a female condom and the increase was greater in the intervention schools (from 42 percent to 77 percent, $\mathrm{p}<.001$ ) compared to the comparison schools (47 percent to 55 percent; $\mathrm{p}<.001)$. When based on the total sample, the percent of intervention school teachers who had seen a female condom rose from 31 percent at baseline to 73 percent at follow up (p < .001 ), while the percent of those in the comparison schools who had seen one rose from 39 percent to 51 percent ( $\mathrm{p}<.001$; data not shown). Thus at the end of Teachers Matter, three-fourths of the intervention school respondents had seen a female condom compared to only half of those in the comparison schools. 
Improvements were also realized in respondents knowing where to procure a female condom, which significantly increased in the intervention schools from 40 percent to 53 percent $(p<.001)$, and from 36 percent to 42 percent in the comparison group $(\mathrm{p}<.05)$. Recalculated to include the total sample, this means that at baseline, 29 percent of the intervention school sample said they knew from where to obtain a female condom, but at follow up this had risen to 50 percent $(\mathrm{p}<.001)$. By comparison, 29 percent of the comparison school sample knew where to get a female condom at baseline, and this rose to 38 percent at follow up. Thus the gains were greater in the intervention schools.

Multivariate analysis revealed that, after controlling for gender, age, level of teacher training, and urbanrural school location, attending Teachers Matter meetings significantly correlates with awareness of the female condom. Those who attended some Teachers Matter meetings were 3.3 times more likely to have seen one (CI: 1.7-6.3), while those who attended all meetings were 5.3 times as likely to have seen one compared to those who did not attend any meetings (CI: 2.5-11.0).

Table 9 Knowledge and attitudes toward female condom use among teachers at baseline and follow up

\begin{tabular}{|c|c|c|c|c|c|c|c|c|c|c|}
\hline & \multicolumn{5}{|c|}{ Intervention } & \multicolumn{5}{|c|}{ Comparison } \\
\hline & \multicolumn{2}{|c|}{ Baseline } & \multicolumn{2}{|c|}{ Follow up } & \multirow[b]{2}{*}{ p } & \multicolumn{2}{|c|}{ Baseline } & \multicolumn{2}{|c|}{ Follow up } & \multirow[b]{2}{*}{$\mathbf{p}$} \\
\hline & $\mathbf{n}$ & $\%$ & $\mathbf{n}$ & $\%$ & & $\mathbf{n}$ & $\%$ & $\mathbf{n}$ & $\%$ & \\
\hline Heard of female condom & 572 & 79 & 622 & 97 & $<.001$ & 665 & 87 & 685 & 93 & $<.001$ \\
\hline Seen female condom^ ${ }^{\wedge}$ & 438 & 42 & 596 & 77 & $<.001$ & 562 & 47 & 627 & 55 & 0.002 \\
\hline $\begin{array}{l}\text { Knows where to acquire } \\
\text { female condom }\end{array}$ & 438 & 40 & 596 & 53 & $<.001$ & 562 & 36 & 627 & 42 & 0.019 \\
\hline
\end{tabular}

${ }^{\wedge}$ Among those who have heard of the female condom

\section{HIV burden}

Teachers continue to be strongly affected by the HIV epidemic in their personal lives, as seen in Table 10. One teacher said:

If one is not infected, one is affected. We have undergone the experience of our relatives suffering from this infection; we have had to take care of them.

Primary school teacher, Thika

The data show that there was a significant increase in the percentage of teachers aware of an HIV-related death in their family in study schools (from 30 percent at baseline to 41 percent at follow up in the intervention schools; $\mathrm{p}<.001$, compared to from 35 percent to 39 percent in the comparison schools; $\mathrm{p}<$ $.05)$. There was also an increase in the proportion of teachers in both study sites reporting that an immediate family member was HIV-positive. 


\section{Hgrizons}

Teachers in intervention schools had been encouraged to talk with their family members and other individuals about HIV, and to share the information they were learning through Teachers Matter. The stigma-related sections of Teachers Matter had urged teachers to avail themselves as sources of support for people living with HIV, and to set a good example. As one teacher explained:

After teaching about this program, some people who are HIV-infected from the community were referred to me. They were very sick. So, I advised them, organized for them to go to the hospital for ARVs. They are ok.

Secondary school teacher, Kwale

Table 10 Personal experience with HIV among teachers at baseline and follow up

\begin{tabular}{|c|c|c|c|c|c|c|c|c|c|c|}
\hline & \multicolumn{5}{|c|}{ Intervention } & \multicolumn{5}{|c|}{ Comparison } \\
\hline & $\mathbf{n}$ & $\%$ & $\mathbf{n}$ & $\%$ & p & $\mathbf{n}$ & $\%$ & $\mathbf{n}$ & $\%$ & $\mathbf{p}$ \\
\hline $\begin{array}{l}\text { Immediate family } \\
\text { member died of } \\
\text { AIDS }\end{array}$ & 563 & 30 & 604 & 41 & $<.001$ & 652 & 35 & 677 & 39 & ns \\
\hline $\begin{array}{l}\text { Immediate family } \\
\text { member infected } \\
\text { with HIV }\end{array}$ & 572 & 18 & 622 & 29 & $<.001$ & 665 & 21 & 685 & 25 & ns \\
\hline 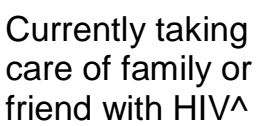 & 217 & 29 & 306 & 31 & ns & 297 & 25 & 297 & 32 & ns \\
\hline
\end{tabular}

${ }^{\wedge}$ Among those who have ever taken care of a family member with HIV

The finding that teachers in the intervention schools were more likely to report personal awareness of HIV in their family could be as a result of these factors. In addition, it is possible that family members may have learnt of a teacher's involvement in Teachers Matter, and felt more confident in confiding to him/her. Some teachers may also have become more willing to disclose familial HIV during the follow-up survey compared to baseline. The findings could also be a result of epidemiologic HIV trends in Kenya, with the epidemic now having reached the "death phase"-i.e., those who were infected during the peak incidence years are now dying of the disease (MOH/NASCOP 2005). Thus there are several factors that could explain the observed results.

At follow up, a third of all teachers in both groups were currently caring for somebody else who had AIDS. For this group, Teachers Matter provided much needed information on care and support:

It taught us how to care for those people living with HIV and how to relate with them. Not the way we used to look down at them and despise them. After going through this program, we know how to relate to them.

Primary school teacher, Thika 


\section{HIV testing}

A key objective of the Teachers Matter project was to increase HIV testing among teachers. While almost all knew where to get tested for HIV, the challenge of the intervention was to influence factors leading to action.

Self-efficacy: An important aspect of encouraging HIV testing is self-efficacy: if individuals are not confident they are able to cope with a positive test result, they may be less likely to want to be tested and find out their status. The data suggest that teachers became more comfortable with the idea of being tested during the study period. The proportion of teachers who said they were not afraid of being tested increased from 47 percent to 54 percent in the intervention group $(\mathrm{p}<.01)$, but a similar increase was documented in the comparison group (from 50 percent to 57 percent; $p<.05$ ). Looking at the other side, the research found that an appreciable proportion of teachers were either "very" afraid or "somewhat" afraid of being tested. At the intervention sites, 53 percent of teachers reported this fear during the baseline, compared to 46 percent during the follow up. At the comparison sites, the figures were 50 percent and 43 percent respectively. Thus this is an area in which teachers need considerable support.

Although many teachers continue to fear being tested, Teachers Matter appears to have planted the seed and some admitted giving it consideration:

That decision ... needs a lot of courage. And ... I have to assess the repercussions ... I'll be there [go for testing]; I've thought of it so many times.

Primary school teacher, Thika

The climate was to go and be tested. It scared some, but we struggled....

Primary school teacher, Kwale

Getting tested: Table 11 describes testing behaviors of the intervention and comparison groups. There were significant increases in the percentage of teachers who had been tested for HIV, but this happened in both intervention and comparison schools (intervention schools: 24 percent to 39 percent [p <.001]; comparison schools: 25 percent to 41 percent $[p<.001])$. Multivariate analysis also showed that the intervention was not significantly associated with HIV testing status, after controlling for the study confounders (data not shown). The fact that comparable increments were seen in both intervention and comparison schools may reflect the possibility that HIV testing was influenced by factors impacting both intervention and comparison areas in a similar manner. HIV is a common topic of discussion nationwide and widely covered in the media, churches, and other places of public dialogue. Thus these factors may have exerted influences beyond the intervention. 


\section{Hgrizons}

Table 11 HIV testing among teachers at baseline and follow up

\begin{tabular}{|c|c|c|c|c|c|c|c|c|c|c|}
\hline & \multicolumn{5}{|c|}{ Intervention } & \multicolumn{5}{|c|}{ Comparison } \\
\hline & \multicolumn{2}{|c|}{ Baseline } & \multicolumn{2}{|c|}{ Follow up } & \multirow[t]{2}{*}{$\mathbf{p}$} & \multicolumn{2}{|c|}{ Baseline } & \multicolumn{2}{|c|}{ Follow up } & \multirow[t]{2}{*}{$\mathbf{p}$} \\
\hline & $\mathbf{n}$ & $\%$ & $\mathbf{n}$ & $\%$ & & $\mathbf{n}$ & $\%$ & $\mathbf{n}$ & $\%$ & \\
\hline Have ever been tested & 572 & 24 & 622 & 39 & $<.001$ & 665 & 25 & 685 & 41 & $<.001$ \\
\hline Number of times ever tested^ & 132 & & 225 & & 0.02 & 166 & & 266 & & ns \\
\hline One & & 61 & & 43 & & & 53 & & 48 & \\
\hline Two & & 21 & & 31 & & & 26 & & 28 & \\
\hline Three or more & & 16 & & 23 & & & 17 & & 21 & \\
\hline
\end{tabular}

${ }^{\wedge}$ Among those who have ever been tested

Overall, the total number of times respondents that had been tested for HIV in their lifetime increased significantly in the intervention group $(\mathrm{p}<.05)$. The percentage of teachers who had been tested twice increased from 21 percent to 31 percent, while the percentage that had tested three or more times increased from 16 percent to 23 percent, making it apparent that the intervention was successful at encouraging those who had already been tested to continue doing so to be sure of their HIV status. There was no significant change in number of times teachers had been tested in the comparison schools.

During the peer educator training, about a third of trainees got tested for HIV for the first time, and others got tested once they started implementing the intervention. As they said:

I had to be a role model so that when I urge the other teachers to go for the testing, I talk from experience.

Primary school teacher, Thika

I was the first person to go [get tested], so as to set the example as to why other teachers should be tested.

Primary school teacher, Kwale

Although much of the emphasis of Teachers Matter was on the individual teacher, they were encouraged to discuss HIV testing with partners and to test together. The data show that while there was an increase in the proportion of teachers who reported that their partners had been tested, this increase was across both intervention and comparison schools (from 25 percent to 41 percent in the intervention schools [p <.001], compared to 26 percent to 41 percent in the comparison schools [p <.001]). Multivariate analysis did not demonstrate any significant association between exposure to the intervention and partner testing (data not shown).

Untested teachers: Among those who had never been tested for HIV, there was no significant change over time in their reasoning for avoiding the test. About a third of all un-tested teachers said they did not have a particular reason why they had never been tested, and an additional third said it was because they did not feel at risk. One teacher explained why he, and others like him, has avoided the test:

I've considered [testing] many times but backed off because of the fear of knowing your status, guilt, stigma, and immediately what will start happening to you when you are told you are positive. 
You see now, for people like us with families, you start feeling guilty...it is the fear of what might come after....

Secondary school teacher, Thika

Untested teachers were asked whether they would consider being tested and the results are presented in Table 12. There was a significant increase in the percent of untested respondents in the intervention schools who would consider testing (from 35 percent to 42 percent; $p=0.004$ ), and a significant decrease in those who said they did not want to be tested (from 39 percent to 27 percent). The changes in the comparison schools were less significant, with the percent wishing to be tested rising from 37 percent to 43 percent, and the proportion saying they did not want to be tested remaining constant at 33 percent $(\mathrm{p}=$ 0.08). However, after controlling for gender, age, level of teacher training, and urban-rural school location, multivariate analysis did not reveal any association between desire to be tested and exposure to the intervention (data not shown).

Table 12 Percent of untested teachers who want to be tested for HIV at baseline and follow up

\begin{tabular}{|c|c|c|c|c|c|c|}
\hline & \multicolumn{3}{|c|}{ Intervention } & \multicolumn{3}{|c|}{ Comparison } \\
\hline & $\begin{array}{c}\text { Baseline } \\
\text { n = 425 } \\
\%\end{array}$ & $\begin{array}{c}\text { Follow up } \\
\mathrm{n}=364 \\
\%\end{array}$ & $\mathbf{p}$ & $\begin{array}{c}\text { Baseline } \\
\mathrm{n}=\mathbf{4 8 7} \\
\%\end{array}$ & $\begin{array}{c}\text { Follow up } \\
\mathrm{n}=400 \\
\%\end{array}$ & $\mathbf{p}$ \\
\hline Want to be tested for HIV & & & .004 & & & ns \\
\hline Yes & 35 & 42 & & 37 & 43 & \\
\hline No & 39 & 27 & & 33 & 32 & \\
\hline Not sure & 27 & 31 & & 31 & 25 & \\
\hline
\end{tabular}

\section{Sexual risk taking}

During both rounds of data collection, about 81 percent of respondents in the intervention schools reported that they were sexually active, and the percent reporting multiple partners remained the same (4 percent at baseline, 6 percent at follow up; $p=0.21$ ). In the comparison schools, the proportion reporting that they were currently sexually active rose slightly from 78 percent at baseline to 83 percent at follow up $(\mathrm{p}=0.02)$. The percent of these reporting multiple partners there remained the same though, 8 percent at baseline and 10 percent at follow up $(\mathrm{p}=0.32)$.

In order to assess risk-taking among teachers, sexually active respondents were asked how many different individuals they had had sex with in the 12 months preceding the survey. However, this question elicited large non-responses, an average of 14 percent in both intervention and comparison schools. Nonetheless, analysis showed that the percent of sexually active respondents who reported multiple partners remained constant at the intervention schools (from 12 percent to 14 percent, $p=0.40$ ), but inched up in the comparison schools (from 12 percent to 17 percent; $p=0.09$ ). Multivariate analysis did not find an association between multiple partnerships and exposure to the intervention (data not shown). Thus exposure to Teachers Matter did not increase or decrease multiple partnerships in the preceding 12 months. 


\section{Hgrizons}

Respondents reporting multiple partners were asked how often they had used condoms with these individuals, with possible responses ranging from "all the time," "almost every time," "sometimes," "hardly ever," and "not at all." It also included an option for "don't know/not sure." Those who said "all the time" were classified against the other categories. The percent of multi-partnered respondents who reported using condoms always in the 12 months preceding the survey remained the same at the intervention schools, at 9 percent during both rounds $(\mathrm{p}=0.93)$. The proportions also remained statistically unchanged in the comparison schools ( 14 percent to 20 percent, $p=0.41$ ). Thus the overwhelming majority of teachers reporting multiple sex partners, 91 percent of those in the intervention schools and 80 percent of those in the comparison schools at follow up, said they were not protecting themselves always and could therefore be at risk for HIV. The sample size was too small for meaningful multivariate analysis.

Respondents with multiple partners were also asked whether they had ever been tested for HIV. Bivariate results showed that individuals with multiple partners were no more likely to report having been tested for HIV compared to their monogamous counterparts at baseline in both intervention and comparison schools (see Table 13). The sample size was too small for meaningful multivariate analysis.

\section{Table 13 Percent of tested teachers by number of partners in the past one year, baseline and follow up}

\begin{tabular}{|c|c|c|c|c|c|c|c|c|c|c|}
\hline & \multicolumn{5}{|c|}{ Baseline } & \multicolumn{5}{|c|}{ Follow up } \\
\hline & \multicolumn{2}{|c|}{$\begin{array}{l}\text { Multiple } \\
\text { partners }\end{array}$} & \multicolumn{2}{|c|}{$\begin{array}{c}\text { One } \\
\text { partner }\end{array}$} & \multirow[b]{2}{*}{$p$} & \multicolumn{2}{|c|}{$\begin{array}{l}\text { Multiple } \\
\text { partners }\end{array}$} & \multicolumn{2}{|c|}{$\begin{array}{c}\text { One } \\
\text { partner }\end{array}$} & \multirow[b]{2}{*}{ p } \\
\hline & $\mathbf{n}$ & $\%$ & $\mathbf{n}$ & $\%$ & & $\mathbf{N}$ & $\%$ & $\mathbf{n}$ & $\%$ & \\
\hline Intervention & 45 & 29 & 300 & 24 & ns & 65 & 37 & 373 & 42 & ns \\
\hline Comparison & 50 & 18 & 366 & 25 & ns & 85 & 31 & 417 & 43 & $<.001$ \\
\hline
\end{tabular}

\section{General HIV knowledge}

One of the objectives of Teachers Matter was to improve the level of participants' knowledge about HIV, and to reduce stigma. During the baseline survey, knowledge was measured by a series of seven true/false questions covering basic information about the HIV epidemic, transmission, and treatment (see Appendix II). Each correct answer was awarded a point, and the percent correct was calculated. The same process was used for the follow-up survey. However, three additional questions were included in the follow-up survey, in order to incorporate emerging HIV information (on discordance, male circumcision, and HIV transmission through saliva).

The mean HIV knowledge rose in the intervention schools from 67 percent to 71 percent ( $p<.001)$, but rose too in the comparison schools, also from 67 percent to 72 percent $(\mathrm{p}<.001)$. Respondents were dichotomized at the mean, with those scoring below the average considered having low knowledge, and those at or above the average considered having high knowledge. Logistic regression analysis was conducted in these groupings and the results show that those who attended all sessions of Teachers Matter were 2.0 times more likely to score above the mean compared to the other groupings (CI: 1.1-3.6). Partial participation was not associated with incremental gains (see Appendix I). 


\section{Stigma}

Another outcome measure Teachers Matter sought to influence was the level of stigma teachers harbored toward people living with HIV. Stigma was measured by a series of six survey questions about attitudes toward people living with HIV and how those people deserve to be treated (see Appendix II).

Respondents whose answers did not include any stigmatizing attitudes were classified at "no stigma," those with one or two answers portraying stigmatizing feelings were scored as "some stigma," and those with more than three stigmatizing answers were classified as "high stigma." Significant reductions in stigma among teachers occurred in both intervention and comparison groups, although the changes were greater in the intervention group. Those with no stigmatizing attitudes increased from 36 percent to 62 percent and those with high stigma decreased from 22 percent to 8 percent in the intervention group ( $\mathrm{p}<$ .001 ; see Table 14), compared to an increase in those with no stigma from 38 percent to 60 percent and a decrease in those with high stigma from 21 percent to 11 percent $(\mathrm{p}<.0010)$ in the comparison group. However, multivariate analysis found that after controlling for gender, age, level of teacher training, and urban-rural school location, there was no significant relationship between level of HIV stigma and exposure to the intervention, suggesting that other factors were influencing the observed changes (data not shown).

Table 14 Changes in HIV knowledge and stigma level among teachers at baseline and follow up

\begin{tabular}{lccc|ccc}
\hline & \multicolumn{3}{c|}{ Intervention } & \multicolumn{3}{c}{ Comparison } \\
& $\begin{array}{l}\text { Baseline } \\
\mathbf{n = 5 7 2}\end{array}$ & $\begin{array}{c}\text { Follow up } \\
\mathbf{n = 6 2 2}\end{array}$ & $\mathbf{p}$ & $\begin{array}{c}\text { Baseline } \\
\mathbf{n = 6 6 5}\end{array}$ & $\begin{array}{c}\text { Follow up } \\
\mathbf{n = 6 8 5}\end{array}$ & $\mathbf{p}$ \\
\hline Mean \% knowledge score & 67 & 71 & $<.001$ & 67 & 72 & $<.001$ \\
Stigma level (\%) & & 62 & $<.001$ & & & $<.001$ \\
$\quad$ None & 36 & 30 & & 41 & 30 & \\
Some & 42 & 8 & & 21 & 11 \\
$\quad$ High & 22 & 0.66 & & 1.33 & 0.76 \\
Mean stigma score & 1.40 & & & & & \\
(out of 6, 0 = no stigma) & & & & &
\end{tabular}




\section{Hgrizons}

\section{Discussion and Recommendations}

Teachers Matter is one of the first well-documented HIV workplace programs in sub-Saharan Africa targeting teachers as the main beneficiaries. It provides an important opportunity not only to assess the needs of teachers as adults who too are infected and affected by HIV, but also to explore the effectiveness of a teacher-centered workplace HIV program. It allows the opportunity to assess whether such an intervention can improve knowledge, attitudes, and HIV prevention practices among this cohort, and also whether a school-based workplace program is able to improve the work environment through confidentiality and job security, the development of coping skills among management and staff, and the dissemination of workplace policies surrounding HIV. Because many workplace programs for teachers in Kenya are likely to use a peer education strategy (e.g., KNUT), it also provides useful lessons for scaling up such interventions.

\section{Successes}

Teachers Matter allowed an enhanced discussion of HIV prevention and treatment technologies, and was particularly successful in dealing with topics teachers were unfamiliar with. For example, it was particularly successful in disseminating the new Education Sector Policy on HIV and AIDS, updating teachers in less common technologies such as female condoms, and introducing them to innovations in HIV management such as post-exposure prophylaxis. Teachers who participated in the intervention were nearly six times more likely to have read (not merely to have heard about) the Education Sector Policy on HIV and AIDS than their colleagues who did not participate, and greater participation was associated with greater likelihood of having read it. Exposure to such workplace policies empowers teachers to know their rights and to ensure that the administration is performing in an ethical and appropriate way. This empowerment in turn translates into teachers becoming more comfortable with discussing HIV issues and supporting those who are infected.

Teachers who participated in the intervention were five times more likely to have seen (not merely heard of) a female condom, and there was a clear dose-response effect. While only 31 percent of teachers at the intervention sites reported having seen a female condom during the baseline survey, this had risen to 73 percent after Teachers Matter. And while the rates at the comparison sites also rose (from 39 percent to 51 percent), clearly Teachers Matter was associated with greater gains in this regard. Likewise, there were sharper gains in awareness of PEP. Teachers exposed to the intervention were nearly 7 times more likely to report being aware of PEP, also with a strong dose response. At baseline, less than four percent of teachers said they had been aware of PEP but after the intervention, a quarter of those in the intervention sites said they were aware of it, compared to only three percent in the intervention sites.

There were also other achievements. For example, although most teachers were aware of male condoms, for many it was the first time they had seen or touched one. Many peer educators cringed when condoms were distributed during training, and several observed their colleagues first before eventually touching one. Trainers spent many hours helping teachers address conflicts such as perceived links between condoms and promiscuity and infidelity. Once teachers were able to become more familiar with male condoms, the intervention proved successful in improving attitudes toward them. Teachers participating in the intervention were 1.7 times more likely to have positive attitudes towards male condoms. 
The intervention was also associated with improvements in knowledge, with those who had attended all sessions more than twice as likely to have high knowledge scores compared to those who had not attended any sessions. With increased knowledge and comfort level gained in discussing HIV issues, teachers may have been more willing to disclose their own HIV burden; the percent reporting HIV infection or AIDS-related death among close family members rose from around a third at baseline to about 40 percent at follow up. Teachers also reported becoming magnets for family and community members. Many said that relatives and friends had approached them to confide in them about their HIV status. Teachers responded in turn, by providing much-needed information on VCT and ARVs, and often became caretakers for such individuals. In accordance with their role as leaders in the community, participating teachers were also called upon by the community to speak to parents and in churches about HIV. This may also partly explain why there was an association between the intervention and teachers' awareness of HIV in their personal settings.

Teachers Matter was highly effective in improving the work environment with regards to HIV. Teachers who participated in the intervention were significantly more likely to say that both the school management and their fellow colleagues were better equipped to cope with HIV at school than they were the year before. In follow-up focus group discussions in the intervention group, many teachers reported increased empathy and support for HIV-positive colleagues, where previously they had been shunned and excluded. The intervention also provided an enabling environment for numerous informal discussions many reported dialogues surrounding HIV testing, stigma, personal relationships with partners, sexual conduct, alcohol use, domestic violence, and other sensitive issues that could now be debated in the staff room. Expressing one's opinions on a topic is often an effective way of solidifying behavior change, and such dialogue served to refine teacher's attitudes toward such issues.

The intervention reached about 2700 teachers at a cost of US\$42,500. This included the costs of preparing and printing the $\mathrm{BCC}$ materials, full costs of training the peer educators including transport and accommodation, full costs of sensitizations for head teachers, and mobile VCT services. This translates into roughly $\$ 16$ per teacher reached.

\section{Challenges}

In some areas, changes occurred in both intervention and comparison schools. For example, reductions in stigma occurred in both schools, making it difficult to attribute such gains to Teachers Matter. We attribute this to concomitant programs HIV information campaigns being conducted in Kenya. Regardless of the cause, it is gratifying to note that stigma levels declined over the course of the intervention.

Teachers Matter aspired to help teachers better assess their risk of HIV at work, and reduce their anxieties that they could be infected by interacting with children. While the intervention reduced the level of concern for some, still nearly 60 percent of teachers said they feared that they could be infected at work. Further discussions revealed that this was in part because many did not have infection control equipment such as first aid kits, gloves, or disinfectant. Thus this remains an area of concern.

Although participants in Teachers Matter had increased levels of HIV testing, there remained a sizable proportion of participants who continue to fear this procedure. Comments from the qualitative study suggest that the "fear" to test is not simple fear, but is a rather complex sentiment wrapping actual fear of 


\section{Hgrizons}

HIV with the guilt and shame of having let people down. Fear of testing among teachers was also fueled by anxiety over facing the consequences of a positive test result. Many teachers commented that if the results of the test were positive, they would be inviting the stigma and discrimination they have witnessed others face upon them, their families, and friends. The fact that teachers are so highly regarded in their communities may result in even harsher self-assessment, feeling they have failed as role models. Teachers are also particularly vulnerable because if they seek VCT, they may discover that some of the counselors are their former students. This complicates HIV testing behavior in a way that may be unique to teachers, and may discourage many from seeking testing.

The study encouraged teachers to learn the HIV status of their partners, but the follow-up survey data show that nearly 60 percent of those with partners do not know this person's status. Therefore couple counseling and testing initiatives are needed for this population. Teachers seemed particularly interested in mobile VCT, and this could be a possible strategy. A mobile VCT counselor can un-intrusively visit schools and test willing teachers. Such a service could potentially extend to homes for teachers who request this service, especially to enable couple counseling and testing.

Although questions about detailed sexual risk taking among the study participants elicited a non-response rate of about 15 percent, available data showed that 14 percent of follow-up respondents in the intervention schools had multiple partners in the 12 months preceding the research. In the comparison schools, about 17 percent did as well. However, 90 percent of these teachers in the intervention schools and 80 percent of their counterparts in the comparison schools said they did not use condoms "always"

during these encounters. Because inconsistent condom use does not confer adequate protection from HIV, programs are needed to help these teachers to protect themselves effectively if they choose to have multiple sex partners. Because there was no association between Teachers Matter and having multiple sex partners or using condoms always, this suggests that more intensive interventions would be needed to elicit the desired behavioral response.

Teachers Matter was also not able to increase perceptions of job security. At the end of the intervention, uncertainty continued over what would happen if their employer discovered they were HIV-positive or what would happen if there was a breach of confidentiality. Much of this confusion is justified: although teachers are now familiar with workplace policies and procedures in theory, there is still ambiguity even among head teachers and school management about the actual steps that must be carried out to comply with these policies. Thus further discussions to help teachers accurately interpret the Education Sector Policy on HIV and AIDS are needed. Other sensitive issues such as breach of confidentiality remained unclear. Future programs can work with teachers to develop school-specific policies, even as more comprehensive national ones are developed.

\section{Lessons Learned}

Teachers Matter was based on the tried and true peer education strategy and used a simple, teacherfriendly, and adult-oriented manual. The intervention and activities were well received by the teachers, as well as by the education sector management at the school, district, and national level. Several lessons were learnt however, that can make future initiatives like these more successful: 


\section{Preparatory activities}

1. The support of the national, district, and school level management was essential. Teachercentered interventions will be more successful if they work closely with these structures.

2. Careful formative research enabled Teachers Matter to build on empirical evidence, and to address the issues teachers had raised. However, the 17-month time-lag between the intervention and follow-up survey likely diluted the measurable results of some topics. Therefore time between research and intervention activities should be minimal. However, additional surveys further out would still be useful, to measure the sustainability of change.

\section{Training of peer educators}

1. It is prudent to train two or more peer educators per school. This can enable an appropriate gender and age balance, and provide important social support when the program experiences challenges. It can also minimize interruptions in case of teacher absenteeism, transfers, and related attrition.

2. It is valuable to build in a mid-term training session in order to bring peer educators together to share experiences and solve mutual problems. Recognizing peer educators with non-monetary awards such as certificates was an effective way of keeping them motivated.

3. During training, it was helpful to develop school-specific workplans to guide the intervention. This enabled the peer educators to remain focused and provided a measure of accountability to the management. It was also important for each peer educator to develop a list of HIV resources in the community, so that s/he could immediately start referring teachers as soon as the program commenced. Programs adapting a similar strategy would find these aspects particularly effective.

\section{Implementing the intervention}

1. Even though programs need to be flexible, setting aside a specific time for Teachers Matter during the school week was valuable and allowed predictability. It was especially effective when the head teacher endorsed the time allocation, and also participated. The time identified is important: teachers preferred the sessions be conducted during lunch time instead of evenings when they are rushing to go home.

2. Reminding teachers that such a workplace initiative is targeted at them and not the students is important. During Teachers Matter, there was a tendency for teachers to revert into their roles as teachers and not adults who are also at risk for HIV. Activities at the beginning of each meeting to allow teachers to reflect on their personal lives may assist teachers to remove their "teacher" hat and consider how the topic of the day is relevant to their private live and behaviors.

3. Providing mobile VCT services to teachers may be a useful approach, as it would reduce the social distance they have to cover to learn their HIV status. 


\section{Hgrizons}

4. Providing educational materials was important and gave teachers something to take home. It also gave peer educators something to give to teachers, increasing their value as sources of information. By staggering the BCC materials over the life of the project rather than giving them out all at once, Teachers Matter was able to offer materials that corresponded with the topic under discussion.

5. Schools are diverse and teacher-centered interventions should plan for an appropriate response. For example, one of the schools in the study was for the visually disabled students, and had visually impaired teachers. Teachers Matter was able to convert some of the materials into Braille. As part of comprehensive risk reduction, initiatives for teachers with disabilities such as the hearing impaired would also be needed.

6. It is helpful to involve groups of people living with HIV: Teachers Matter worked with many people living with HIV, both as resource persons and as vendors for the materials prepared for the project. People living with HIV were employed as speakers where possible to talk with attendees. These speakers were exceptionally powerful and often left the teachers challenged but impressed.

7. Supportive monitoring was key to the success of the project. Quarterly visits kept the peer educators motivated and goal-oriented. The peer educators' diaries provided essential snap-shots about activities within a specific school.

8. Anticipate requests for compensation: In the early stages, there were numerous requests from teachers for "sitting allowances", a Kenyan practice associated with payment for attending meetings. Teachers believed that peer educators were receiving financial compensation, and agitated for a part of it. Teachers Matter did not pay peer educators; rather the project recognized them in non-monetary ways such as additional training, availing them with BCC materials, and providing supportive supervision during the intervention. Peer educators also received certificates of recognition after the training. Because the program involved the head teachers from the start, they were also able to help whenever monetary compensation issues came up. Programs implementing a similar activity therefore need to select committed peer educators and work closely with the school management to minimize some of the challenging requests.

9. Partial participation will only achieve limited results: The evaluation data show that the greatest impact was achieved among teachers who attended all the sessions of Teachers Matter. For the most part, those attending only some of the sessions did not register substantial enough gains, suggesting that partial participation may be ineffectual. Therefore future interventions should be structured in a manner to enable full participation among teachers. This could be done by integrating the program into the school curriculum, or dedicating other appropriate time to it. Teachers could also be recognized for completing the course, for example by being awarded a certificate of participation or similar honor. 


\section{Appendix I \\ Adjusted Odds Ratio of Specific Outcome by Exposure to Teachers Matter}

\begin{tabular}{|c|c|c|c|}
\hline \multirow{2}{*}{$\begin{array}{l}\text { Outcome variable } \\
\text { Believe fellow teacher can cope with HIV in the workplace } \\
(n=514)\end{array}$} & \multirow[t]{2}{*}{ AOR^ $^{\wedge}$} & \multicolumn{2}{|c|}{$95 \% \mathrm{Cl}$} \\
\hline & & & \\
\hline Did not attend TM meetings & 1.0 & & \\
\hline Attended some TM meetings & $1.7^{*}$ & 0.9 & 3.1 \\
\hline Attended all TM meetings & $3.6^{*}$ & 1.9 & 6.7 \\
\hline \multicolumn{4}{|c|}{$\begin{array}{l}\text { Believe school management can cope with HIV in } \\
\text { workplace }(n=515)\end{array}$} \\
\hline Did not attend TM meetings & 1.0 & & \\
\hline Attended some TM meetings & 1.0 & 0.6 & 1.8 \\
\hline Attended all TM meetings & $1.7^{*}$ & 0.9 & 3.2 \\
\hline \multicolumn{4}{|c|}{ Read Education Sector Policy on HIV and AIDS $(n=536)$} \\
\hline Did not attend TM meetings & 1.0 & & \\
\hline Attended some TM meetings & $2.0^{*}$ & 1.0 & 3.9 \\
\hline Attended all TM meetings & $5.7^{*}$ & 2.8 & 11.2 \\
\hline \multicolumn{4}{|l|}{ Aware of PEP $(n=509)$} \\
\hline Did not attend TM meetings & 1.0 & & \\
\hline Attended some TM meetings & $2.6^{*}$ & 1.2 & 5.9 \\
\hline Attended all TM meetings & $6.7^{*}$ & 3.0 & 15.2 \\
\hline \multicolumn{4}{|c|}{ Positive attitude toward male condoms $(n=536)$} \\
\hline Did not attend TM meetings & 1.0 & & \\
\hline Attended some TM meetings & 1.0 & 0.6 & 1.7 \\
\hline Attended all TM meetings & 1.7 & 0.9 & 3.1 \\
\hline \multicolumn{4}{|c|}{ Have seen a female condom $(n=483)$} \\
\hline Did not attend TM meetings & 1.0 & & \\
\hline Attended some TM meetings & $3.3^{*}$ & 1.7 & 6.3 \\
\hline Attended all TM meetings & $5.3^{*}$ & 2.5 & 11.0 \\
\hline \multicolumn{4}{|c|}{ High level of HIV/AIDS knowledge $(n=536)$} \\
\hline Did not attend TM meetings & 1.0 & & \\
\hline Attended some TM meetings & 1.4 & 0.8 & 2.3 \\
\hline Attended all TM meetings & $2.0^{*}$ & 1.1 & 3.6 \\
\hline
\end{tabular}

${ }^{\wedge}$ Controlling for sex, age, urban-rural location of school and level of teacher training; *Association between outcome and exposure to Teachers Matter significant $(p \leq 0.05)$ 


\section{Hgrizons}

\section{Appendix II \\ Measures Used}

\section{Knowledge and attitudes toward condoms}

1. I believe male condoms decrease a man's sexual pleasure (disagree)

2. I believe male condoms are quite convenient to use (agree)

3. I believe male condoms can be reused (disagree)

4. I believe male condoms are effective in preventing HIV if used properly (agree)

5. I fear I would lose respect if I suggested to a woman we use a condom (disagree)

6. I would NOT be embarrassed to buy condoms (agree)

7. I feel that using a condom shows you care for your partner (agree)

8. I think it is alright for a married woman to ask her husband to use a condom (agree)

9. I think it is acceptable for a married man to offer to use condoms with his wife (agree)

\section{Knowledge}

1. More women are infected with HIV in Kenya than men (true)

2. HIV and AIDS are the same thing (false)

3. Someone can be infected with different types of HIV at the same time (true)

4. If you go for voluntary counseling and testing (VCT), you must take the HIV test (false)

5. There is now a cure for AIDS (false)

6. Sexually transmitted diseases increase the risk of HIV (true)

7. If an HIV-positive woman becomes pregnant, the chances of infecting her unborn baby are 100 percent (false)

8. It is possible for a sexually active couple to be discordant (true; question in follow up only)

9. Circumcision makes a man immune to HIV (false; question in follow up only)

10. One can get HIV through saliva (false; question in follow up only)

\section{Stigma}

1. If a student at your school has HIV but is not sick, should he or she be allowed to continue attending school? (Yes)

2. If food was prepared for you by someone you knew or suspected has HIV, would you eat it? (Yes)

3. If you knew a shopkeeper or food seller had HIV, would you buy food from him/her? (Yes)

4. How afraid would you are of people living with AIDS? Would you say you feel very afraid, afraid, a little afraid, not at all afraid (not at all afraid)

5. People with HIV should be made public so that others can avoid them (disagree)

6. People who are infected with HIV through sex have got what they deserve (disagree) 


\section{References}

American Federation of Teachers (AFT). 2005. "Kenyan teachers lead the fight against AIDS" retrieved from http://www.aft.org/topics/international/solidarity/Africa-AIDS-Kenyareport.htm

Bennel, P. 2006. Anti-retroviral drugs are driving down teacher mortality in sub-Saharan Africa. Brighton, UK. Unpublished report, Skills for Development.

Brouillard-Coyle, C. et al. 2006. "Teachers as conduits for a school-based HIV intervention in Kenya," Journal of Sex Research 43(1).

Clark, A. 2001. “AIDS decimates African teachers,” Bulletin of the WHO 79(10): 999.

Cohen, D. 2002. "Human capital and the HIV epidemic in sub-Saharan Africa," Working Paper 2. Geneva: ILO Program on AIDS and the World Bank.

Comtex Newswire Service. 2002. "HIV/AIDS kills 7500 Malawian teachers annually," Comtex Newswire Service, African Eye news Service/All Africa Global Media, Feb 04.

Connell, R. W. 1987. Gender and Power. Stanford, California: Stanford University Press.

Goliber, Thomas. 2000. "Exploring the implications of the HIV/AIDS epidemic for educational planning in selected African countries: The demographic question." Washington, DC: World Bank.

Grassly, N.C. et al. 2003. "The economic impact of HIV/AIDS on the education sector in Zambia," AIDS 17: $1039-1044$.

Mail and Guardian. 2001. "HIV/AIDS barometer," accessed Dec 24, 2001. www.mg.co.za/mg/za/archive/2001nov/features/nov01-aidsbarom.html.

McElligot, Margaret. 2005. "Innovative program targets South African teachers," retrieved from http://allafrica.com/stories/200510040234.html.

Kelly, M. 2000. Planning for education in the context of HIV/AIDS. Paris: International Institute for Educational Planning.

Kimani, M., K. Kiragu, and C. Manathoko. 2005. "HIV/AIDS and teachers in Kenya: Results of a baseline survey," Horizons Research Summary. Nairobi: Population Council.

Ministry of Health/NASCOP. 2005. AIDS in Kenya, $7^{\text {th }}$ ed. Nairobi: NASCOP/Ministry of Health.

Peterson, J. and R. DiClemente (eds). 2000. Handbook of HIV Prevention. New York: Kluwer Academic/Plenum Publishers.

Pevzner, E. 2005. "Teachers confronting the HIV epidemic: Skills for teaching and survival." Chapel Hill: University of North Carolina. 


\section{Hgrizons}

Prochaska, J.O., C. C. DiClemente, and J.C. Norcoss. 1992. "In search of how people change: Application to addictive behaviors," American Psychologist 47: 1102-1114.

Republic of Kenya/Ministry of Education. 2004. "Education sector policy on HIV and AIDS.” Nairobi: UNESCO.

UNAIDS. 2006. "2006 report on the global AIDS epidemic.” Geneva: UNAIDS.

UNESCO and ILO. 2006. "An HIV and AIDS workplace policy for the education sector in southern Africa." Paris: UNESCO.

- 2006. "Supporting HIV-positive teachers in east and southern Africa," Technical Consultation Report. Nairobi: UNESCO. 


\section{Hgrizons}

Horizons is a global operations research program designed to:

- Identify and test potential strategies to improve HIV/AIDS prevention, care, and support programs and service delivery.

- Disseminate best practices and utilize findings with a view toward scaling up successful interventions.

\section{(2) Population Council}

Horizons is implemented by the Population Council in collaboration with

- International Center for Research on Women (ICRW)

- International HIV/AIDS Alliance

- PATH

- Tulane University

- Family Health International (FHI)

- Johns Hopkins University

For more information, please contact:

Horizons Program, Communications Unit 4301 Connecticut Ave, NW Suite 280 Washington, DC 20008 USA

Tel: 202-237-9400

Fax: 202-237-8410

Email: horizons@popcouncil.org www.popcouncil.org/horizons 